\title{
Turbulent Velocity-Variance Profiles in the Stable Boundary Layer Generated by a Nocturnal Low-Level Jet
}

\author{
ROBERT M. BANTA \\ Chemical Sciences Division, National Oceanic and Atmospheric Administration/Earth System Research Laboratory, \\ Boulder, Colorado \\ Yelena L. Pichugina \\ Cooperative Institute for Research in Environmental Sciences, and Chemical Sciences Division, National Oceanic and Atmospheric \\ Administration/Earth System Research Laboratory, Boulder, Colorado \\ W. Alan Brewer \\ Chemical Sciences Division, National Oceanic and Atmospheric Administration/Earth System Research Laboratory, \\ Boulder, Colorado
}

(Manuscript received 31 October 2005, in final form 20 February 2006)

\begin{abstract}
Profiles of mean winds and turbulence were measured by the High Resolution Doppler lidar in the strong-wind stable boundary layer (SBL) with continuous turbulence. The turbulence quantity measured was the variance of the streamwise wind velocity component $\sigma_{u}^{2}$. This variance is a component of the turbulence kinetic energy (TKE), and it is shown to be numerically approximately equal to TKE for stable conditions-profiles of $\sigma_{u}^{2}$ are therefore equivalent to profiles of TKE. Mean-wind profiles showed lowlevel jet (LLJ) structure for most of the profiles, which represented 10-min averages of mean and fluctuating quantities throughout each of the six nights studied. Heights were normalized by the height of the first LLJ maximum above the surface $Z_{X}$, and the velocity scale used was the speed of the jet $U_{X}$, which is shown to be superior to the friction velocity $u_{*}$ as a velocity scale. The major results were 1 ) the ratio of the maximum value of the streamwise standard deviation to the LLJ speed $\sigma_{u} / U_{X}$ was found to be 0.05 , and 2) the three most common $\sigma_{u}^{2}$ profile shapes were determined by stability (or Richardson number Ri). The least stable profile shapes had the maximum $\sigma_{u}^{2}$ at the surface decreasing to a minimum at the height of the LLJ; profiles that were somewhat more stable had constant $\sigma_{u}^{2}$ through a portion of the subjet layer; and the most stable of the profiles had a maximum of $\sigma_{u}^{2}$ aloft, although it is important to note that the Ri for even the most stable of the three profile categories averaged less than 0.20 . The datasets used in this study were two nights from the Cooperative Atmosphere-Surface Exchange Study 1999 campaign (CASES-99) and four nights from the Lamar Low-Level Jet Project, a wind-energy experiment in southeast Colorado, during September 2003.
\end{abstract}

\section{Introduction}

The nocturnal low-level jet (LLJ) has an important role in the generation of shear in the layer between the jet maximum or "nose" and the earth's surface. This shear is often an important source of turbulence and turbulent fluxes in the nighttime boundary layer (Mahrt et al. 1979; Lenschow et al. 1988; Smedman et al. 1993,

\footnotetext{
Corresponding author address: Robert M. Banta, National Oceanic and Atmospheric Administration/Earth System Research Laboratory (CSD3), 325 Broadway, Boulder, CO 80305.

E-mail: robert.banta@noaa.gov
}

1995, 1997; Tjernström and Smedman 1993; Mahrt 1999; Mahrt and Vickers 2002; Banta et al. 2002, 2003). Accurate determination of turbulent fluxes is important for transport and diffusion applications, including air quality and emergency response, and for improvements in the representation of these processes in numerical weather prediction (NWP) models (Beyrich 1994; Mahrt 1998; Andreas et al. 2000; Banta et al. 1998, 2005).

Two types of vertical turbulence structure have been identified, one the "traditional" boundary layer, in which turbulence is generated at the surface and transported upward (Fig. 1), in contrast to the second type, where turbulence is transported downward from a pri- 
"TRADITIONAL" Boundary Layer
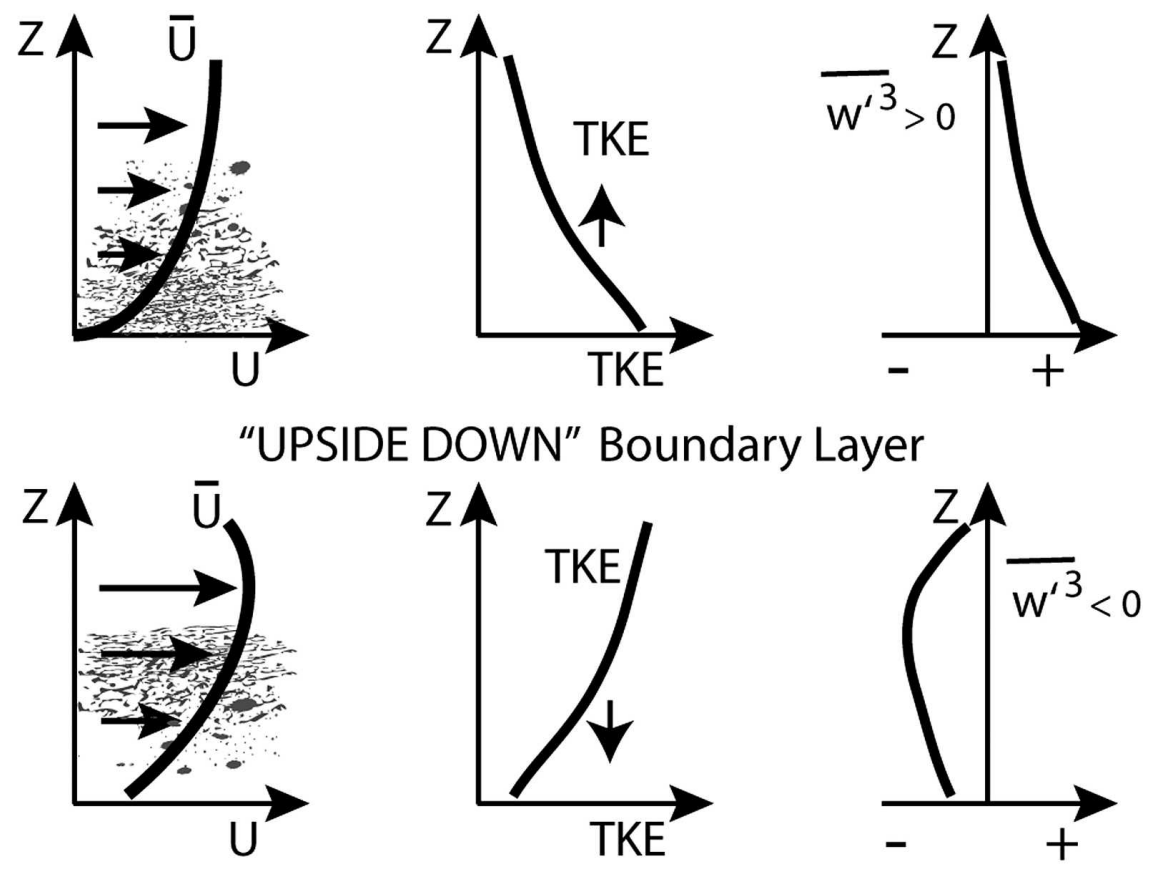

FIG. 1. Schematic of structure of (top) traditional boundary layer vs (bottom) upside-down boundary layer according to criteria of Mahrt and Vickers (2002). (left) Mean horizontal wind speed profiles with turbulence regions shaded; (center) TKE or velocity-variance profiles; and (right) vertical turbulent transport of TKE (triple correlation) term in TKE budget, of which $\sigma_{w}^{3}$ is a component.

mary source aloft in the boundary layer. The latter has been referred to as an "upside-down boundary layer" (Mahrt 1999; Mahrt and Vickers 2002). Examples of these structures from data taken during the Cooperative Atmosphere-Surface Exchange Study 1999 campaign (CASES-99) are given in Mahrt and Vickers (2002), Banta et al. (2002), and Balsley et al. (2006).

A number of studies have presented measurements of turbulence quantities through LLJs in stable atmospheric conditions, as well as profiles for stable cases where no low-level wind maximum (nose) could be defined. In studies of LLJ structure over the Great Plains and the cold Baltic Sea using aircraft slant profiles, TKE was found to decrease with height from a maximum value at the surface to a minimum at the top of the SBL (Lenschow et al. 1988; Smedman et al. 1993, 1995; Tjernström and Smedman 1993), indicating traditional rather than upside-down structure according to the criteria described in Mahrt and Vickers (2002). Recent large-eddy simulation (LES) results indicate a maximum of TKE (or velocity variance) very close to the surface (e.g., Kosović and Curry 2000; Saiki et al. 2000) in agreement with the aircraft profile results.

An important question for turbulent fluxes in the nocturnal stable boundary layer (SBL) is, therefore, what is the shape of the profile of turbulent-velocity fluctuations in the subjet layer? This is an important overall issue in the stable boundary layer because the local-scaling approach, which has been used to relate fluctuating quantities (variances and covariances or fluxes) to each other, requires a profile of some fluctuating quantity to actually produce a model of the SBL (Nieuwstadt 1984).

In the present study we present profiles-individual and composite - of horizontal streamwise velocity variances $\sigma_{u}^{2}$ and standard deviations $\sigma_{u}$ observed by Doppler lidar through vertical regions that include nocturnal LLJs, obtained during two field campaigns over the Great Plains of the United States. We show that these variances are closely related to TKE and, thus, that TKE profiles should have a shape very similar to the variance profiles. The profiles are from nights with strong LLJs, with peak speeds generally greater than 15 $\mathrm{m} \mathrm{s}^{-1}$, and weak stability, with bulk or jet Richardson numbers (Banta et al. 2003) less than 0.3; these cases are thus in the weakly stable regime, as indicated by $\mathrm{W}$ in Fig. 2. All nights had a cold surface relative to the SBL and a strong, surface-based inversion layer extend- 


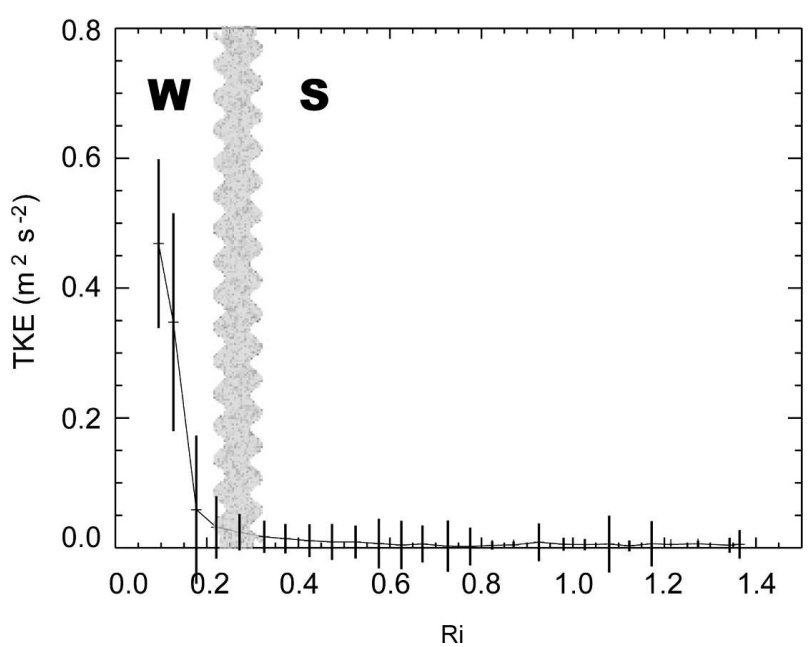

FIG. 2. Plot of TKE vs bulk Ri after Banta et al. (2003). TKE data were from near the top of the CASES-99 60-m tower, and Ri was calculated between the 5- and 55-m levels on the tower. TKE data were averaged for $\mathrm{Ri}$ intervals of 0.05 using the same data and technique as in Banta et al. (2003, cf. their Fig. 8a). Curved solid line connects the median values of TKE for each Ri bin, and vertical error bars indicate \pm 1 standard deviation for data in each bin. W indicates the weakly stable regime considered in this study, $\mathrm{S}$ denotes the strongly stable regime, and the vertical shaded region shows the approximate extent of the transitional regime.

ing upward to approximately the height of the LLJ nose. As shown in Fig. 2, the smallest category of Ri was centered on 0.1 , indicating that the cases studied here were all distinctly stable despite relatively strong LLJ speeds.

The instrument used to measure these profiles was a ground-based, scanning Doppler lidar, the HighResolution Doppler Lidar (HRDL), developed and deployed by the Environmental Technology Laboratory (ETL) of the National Oceanic and Atmospheric Administration (NOAA). The two field projects where data were obtained were CASES-99 and the Lamar Low-Level Jet Project of September 2003 (LLLJP-03).

\section{Background, instrumentation, and approach}

\section{a. Turbulence profiles in the $S B L$}

The SBL under strong wind conditions has been studied for several decades. It has been characterized as a deep traditional boundary layer (Mahrt and Vickers 2002), having a self-similar structure (Sorbjan 1988) and continuous turbulence throughout its depth (Nieuwstadt 1984). A connection between LLJ-generated shear and turbulence was made by Mahrt et al. (1979). They used hourly profiles of mean wind speed $U(z)$ and potential temperature $\theta(z)$ at vertical resolutions of
50-100 $\mathrm{m}$ or better, available from rawinsonde and pibal ascents from several observational programs, to calculate profiles of $\mathrm{Ri}$ and from them, to infer the presence of turbulence. Mean wind profiles were chosen that showed LLJ structure. The accompanying $\operatorname{Ri}(z)$ profiles showed a strong peak in stability at the jet nose, where the shear goes to zero, implying suppressed turbulence at this level. Much smaller Ri values in the shear zone below the jet were interpreted as indicating significant turbulent mixing in the layer below the jet. An aircraft slant profile and turbulence data from instrumented towers supported the existence of turbulence in the subjet layer.

Studies where turbulence profiles were measured have typically found a maximum of turbulence quantities at the surface, decreasing monotonically to a minimum at the top of the SBL - traditional boundary layer structure. Caughey et al. (1979) found this structure using data obtained between dusk and midnight from a 32-m tower and a tethered-balloon system during the 1973 Minnesota project, and Nieuwstadt (1984) found similar SBL structure in turbulence measurements on the 200-m Cabauw tower in the Netherlands. Aircraft slant-path profiles at dawn and dusk over Oklahoma also revealed traditional structure to the SBL (Lenschow et al. 1988; Sorbjan 1988). Although LLJ structure could be detected in many profiles presented in these studies, the role of the LLJ in generating turbulence was not emphasized.

Subsequent to the study of Mahrt et al. (1979), the connection between LLJs and turbulent mixing was further explored in a comprehensive series of measurement projects over the Baltic Sea using instrumented towers, serial rawinsonde and pibal ascents, and aircraft slant-path profiles (Smedman et al. 1993, 1995, 1997, 2004; Tjernström and Smedman 1993). In this region, the frictional decoupling leading to LLJ acceleration via the Blackadar (1957) mechanism was accomplished by spatial (quasi Lagrangian) advection of columns of air from warm land over cold sea surfaces, rather than temporal (Eulerian) nocturnal surface cooling (Högström and Smedman 1984). The many profiles of mean and turbulence quantities presented or analyzed reveal a prevalence of traditional structure. Comparisons of turbulence measurements for profiles with and without LLJ structure show distinct differences, including a much more distinct spectral gap for cases with LLJ. The suppression of low-frequency spectral energy in the gap region was attributed to the inhibition of larger-scale fluctuations, such as gravity waves and two-dimensional inactive turbulence, by the presence of the jet (Smedman et al. 1995, 1997). Smedman et al. (1995) draw parallels between the atmospheric SBL and laboratory 
boundary layers or laboratory wall jets, noting that the proximity of the LLJ to the surface (in other words, the height of the jet maximum $Z_{X}$ ) influences the magnitudes of low-level turbulence variables. This resemblance to laboratory flows suggests that wind-tunnel and other laboratory studies, such as those of Ohya et al. (1997) and Ohya (2001), are relevant to the atmospheric SBL.

Turbulence-profile observations in the weakly stable boundary layer have thus shown traditional boundary layer structure. Analytical models of turbulence profiles for the stationary, horizontally homogeneous SBL with continuous turbulence also show this structure. Nieuwstadt (1984) derived such a model by solving an abbreviated form of the equations of motion after setting $\mathrm{Ri}=\mathrm{Ri}_{f}=0.2$, where $\mathrm{Ri}$ is the Richardson number and $\mathrm{Ri}_{f}$ is the flux Richardson number. The result was a traditional boundary layer structure, with maximum fluxes and variances at the surface decreasing with height to 0 at $z / h=1$, where $h$ is the SBL depth. The model kinematic stress, defined to be $\tau(z)$, decreases as the $3 / 2$ power of height: $\tau / u_{*}^{2}=(1-z / h)^{3 / 2}$, and the heat flux $\langle w \theta(z)\rangle$, where the brackets indicate horizontal or temporal averaging, decreases linearly: $\langle w \theta(z)\rangle /$ $\left\langle w \theta_{0}\right\rangle=1-z / h$. Lenschow et al. (1988) derived a similar model of the SBL, but with a thermodynamic energy equation that was expanded to include a radiative cooling profile. In the resulting model the momentum flux decreased as the 1.75 power of $z$ and the heat flux, as $\mathrm{z}^{3 / 2}$. Sorbjan (1988) recommended 1.5 and 2.0 for the values of these exponents, respectively. Numerical large-eddy simulation runs also reproduce this behavior with a maximum at or just above the surface (Kosović and Curry 2000; Saiki et al. 2000; Mason and Derbyshire 1990).

Although observational and modeling studies of the SBL cited so far have overwhelmingly shown traditional boundary layer structure, the question of the shape of the turbulence profiles in the SBL is far from settled. Smedman et al. (1995) interpreted their findings as showing that turbulence produced in the shear layer below $Z_{X}$ is transported downward by the pressure transport term to layers near the surface. Mahrt (1999) referred to this downward transport of turbulence from a source region of shear production aloft as an upside-down boundary layer configuration. Mahrt and Vickers (2002) refined the definition of this type of boundary layer as one in which TKE (or $\sigma_{w}^{2}$ ) increases with height, turbulent fluxes (e.g., $\tau$ and $\langle w \theta\rangle$ ) likewise increase with height, and the turbulent transport of TKE or of velocity variances (e.g., $\sigma_{w}^{3}$ ) is negative. Clear evidence of upside-down structure has been found using CASES-99 data (Mahrt and Vickers 2002;
Banta et al. 2002; Balsley et al. 2006). Upside-down structure with TKE increasing with height is clearly inconsistent with traditional boundary layer structure, as summarized in Fig. 1. Thus, it is still of great interest to reconcile the observations of upside-down structure with the large body of data showing that the continuous-turbulence, strong-LLJ SBL should have traditional structure.

In each of these atmospheric studies, turbulent velocities were scaled by the surface-layer friction velocity $u_{*}$ and heights were normalized using the boundary layer depth $h$. The definition of $h$ varied from ones based on mean quantities (Tjernström and Smedman 1993) to ones based on the decrease with height of turbulence quantities, for example, the height where the heat flux $H$ decreases to $5 \%$ of its surface value (Caughey et al. 1979), where the TKE similarly decreases by $95 \%$ (Lenschow et al. 1988; Sorbjan 1988), or where sodar backscatter decreases abruptly (Nieuwstadt 1984; Beyrich 1994). Mahrt et al. (1979) argue that the height of the LLJ speed maximum, abbreviated here as $Z_{X}$, represents an "upper bound to the vertical extent of turbulent transport," because of the peak in stability (Ri) at this level, and refer to it as the top of the momentum boundary layer. They show that the depth of the nocturnal temperature inversion $Z_{I}$ increases in time through the night to become routinely larger than $Z_{X}$, which they found tended to stay constant or even decrease somewhat in time. In the present study we further refine the definition of $Z_{X}$ to be the height of the first wind speed maximum above the surface (Banta et al. 2002, 2003), representing the depth of the surface-based shear layer.

Profiles of the terms of the TKE budget were evaluated to determine the processes controlling the structure of the vertical turbulence profiles. The profile was maintained by a near balance between shear production and dissipation throughout the depth of the SBL (Lenschow et al. 1988; Sorbjan 1988; Tjernström and Smedman 1993; Smedman et al. 1993, 1995), and the suppression of TKE by stratification was small but nonzero. The small imbalance found by Smedman et al. $(1993,1995)$ was attributed to the term representing vertical transport by turbulent pressure fluctuations.

Formulating flux and variance statistics depends on the ability to define conditions under which the SBL can be considered reasonably stationary (Vickers and Mahrt 2003, 2006). An almost defining property of the SBL, however, is that it is nonstationary- that its structure can evolve significantly over time scales of an hour or so. Caughey et al. (1979) and Nieuwstadt (1984) argue that the time scale of the turbulent processes in stable conditions is much smaller than the evolution 
time of the mean SBL structure. As a consequence, the "turbulence is continuously in equilibrium with the slowly changing mean field" (Nieuwstadt 1984). This view justifies calculating ratios of turbulence quantities and expressing turbulence quantities in terms of mean gradients or functions of mean gradients (e.g., Ri), as long as the means and fluctuations are with respect to the short averaging time scales appropriate to the turbulence.

Relationships between boundary layer structure and stability have been proposed in many studies (e.g., Holtslag and Nieuwstadt 1986; Van de Weil et al. 2003). Mahrt et al. (1998) identified three regimes, weakly stable, transitional, and strongly stable, based on $z / L$, where $L$ is the Monin-Obukhov length, and Grachev et al. (2005) added a fourth regime in the long-lived arctic SBL, a turbulent Ekman regime between the transitional and strongly stable regimes. Banta et al. (2003) showed that the TKE in the middle of the shear layer below the jet could be related to a bulk Ri or a "jet Ri" based on LLJ properties (height and speed) and the vertical $\theta$ gradient. The diagram illustrating the relationship between Ri and TKE from CASES-99 data is given in Fig. 2, where likely regions of the weakly (W) and strongly (S) stable regimes are indicated. A similar diagram from the Lamar project (Banta et al. 2004) showed the same behavior qualitatively and quantitatively, and recent results from SBLs in the Arctic show a similar dependence on a bulk Ri (Grachev et al. 2005).

\section{b. Measurements}

The CASES-99 field campaign consisted of a significant deployment of surface, airborne, and remote sensing instrumentation to study the nocturnal stable boundary layer, as discussed by Poulos et al. (2002). One of the instruments deployed was the highresolution Doppler lidar (HRDL) described by Grund et al. (2001) with modifications detailed in Wulfmeyer et al. (2000). HRDL emits and receives backscatter from IR light pulses, which are used to probe the aerosol backscatter and Doppler velocity structure of the atmosphere. The range of HRDL during CASES-99 was $\sim 2 \mathrm{~km}$, the spatial resolution of the velocity measurements was $30 \mathrm{~m}$ in range, and the velocity precision was $\sim 10 \mathrm{~cm} \mathrm{~s}^{-1}$. HRDL data have been used in CASES-99 studies of LLJ structure (Banta et al. 2002, 2003), atmospheric waves (Blumen et al. 2001; Newsom and Banta 2003; Fritts et al. 2003; Sun et al. 2004), density currents (Sun et al. 2002), late-afternoon nearneutral boundary layer structure (Drobinski et al. 2004), and as a dataset for demonstrating fourdimensional variational data assimilation (4DVAR) techniques for Doppler lidar (Newsom and Banta 2004a,b). Data for the present study were from 25 and 27 October, two of the nights identified by Banta et al. (2002) as high-wind nights. The third high-wind night (28 October) had an incomplete dataset and was not used.

HRDL was also a key instrument in the Lamar LowLevel Jet Project of 2003, which was organized to investigate nocturnal SBL winds at a site being developed for wind energy. The formation of LLJs during nighttime is very important for wind energy operations. LLJs provide enhanced wind speeds to drive the turbines. Adversely, one issue is the premature failure of turbine hardware as a result of significant nocturnal bursts of turbulence (Kelley et al. 2004). To address these issues, a late-summer field project was organized in early September 2003 at a High Plains location south of the town of Lamar in southeastern Colorado (Kelley et al. 2004; Pichugina et al. 2004; Banta et al. 2004). LLLJP-03 instrumentation included a $120-\mathrm{m}$ tower instrumented at four levels and a three-component Doppler sodar operated over two summers, and HRDL, which was deployed from 1 through 16 September. The tower instruments included three-axis sonic anemometers mounted at heights of 54, 67, 85, and $116 \mathrm{~m}$ to provide threecomponent wind and temperature data at a sampling rate of $20 \mathrm{~Hz}$. Approximately 120 hours of nighttime HRDL data were collected from local sunset $(\sim 0100$ UTC) until 1000-1200 UTC, which was just before sunrise. Datasets for 11 entire nights were obtained, including five high-wind nights, of interest here. Data in the present study are from four of these nights $(5,6,9$, and 15 September), when the LLJ speed exceeded $20 \mathrm{~m} \mathrm{~s}^{-1}$. The dataset for the fifth night (10 September) was incomplete, so it was not included in this study.

Bulk Richardson numbers were calculated from the tower data as described in Banta et al. (2003). The gradients in the bulk Ri calculation

$$
\mathrm{Ri}=\frac{g \Delta \theta / \Delta z}{\theta(\Delta U / \Delta z)^{2}}
$$

were determined from 1-min means of sonic anemometer data between the 5-m and 55-m levels of the CASES-99 tower and between the 54-m and 116-m levels of the Lamar tower. Gradient Ri values were also computed between adjacent levels of the CASES tower above $15 \mathrm{~m}$ and between adjacent levels of the Lamar tower. These Ri values tended to be constant with height and equal to the bulk value, as a result of the roughly linear profiles of $U$ and $\theta$ between the top of the surface layer and $Z_{X}$, as previously noted by Banta et al. (2003; see also Poulos et al. 2002). 


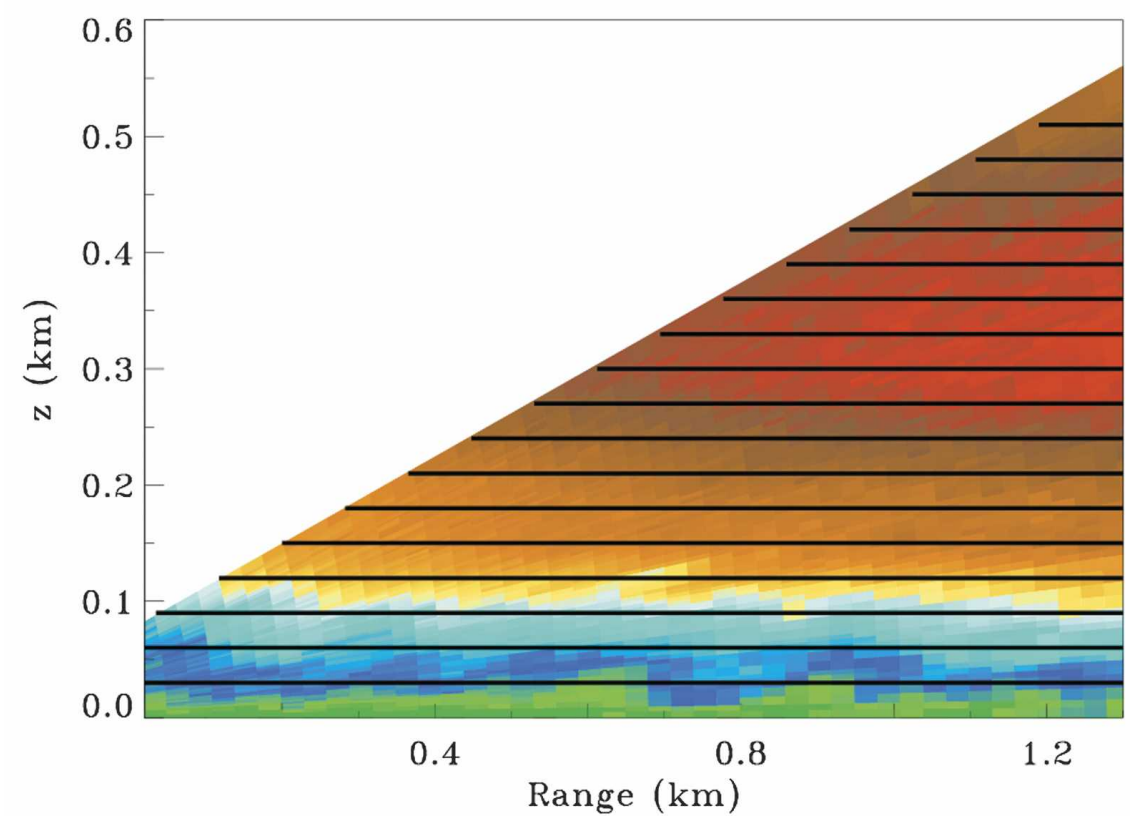

FIG. 3. Vertical-slice scan for 0333 UTC 9 Sep 2003, during the Lamar project, illustrating the vertical binning procedure. Vertical axis is height $(\mathrm{km})$, horizontal axis is horizontal distance from the HRDL position at $(0,0)$, and the color bar indicates wind speed $\left(\mathrm{m} \mathrm{s}^{-1}\right)$. Means and variances were calculated over data within each horizontal band and assigned the height of the midpoint of each band to form vertical profiles. Width of each band $\Delta \mathrm{z}$ depicted here is $30 \mathrm{~m}$ for illustration, but actual intervals used for analysis were 10,5 , and $1 \mathrm{~m}$.

The scanning procedure generally employed during CASES-99 and LLLJP-03 was to perform repeated elevation (vertical slice) scans aligned with the mean wind direction for periods of 10-20 min or more. The mean wind direction was determined by first performing $360^{\circ}$ conical azimuth scans, then calculating vertical profiles of the mean (spatially averaged) horizontal wind direction and speed using the velocity-azimuthdisplay (VAD) technique (Browning and Wexler 1968; Banta et al. 2002), and noting the wind direction from the VAD profiles. We repeated this procedure by measuring the LLJ direction with VAD scans every $\sim 20-30$ min, adjusting the direction of the vertical-slice scans accordingly. During LLLJP-03 Doppler sodar wind profiles were also available in real time at 10 -min intervals, and we used these to monitor and adjust for wind-direction changes between the lidar VAD sequences. Thus, the lidar pointing angle was routinely within $\sim 15^{\circ}$ of the mean wind, which often veered in time through the night from southeasterly to southwesterly, especially during the Lamar project.
Directional shear with height on these strong-wind nights was generally small. A full $360^{\circ}$ conical scan typically took $\sim 2 \mathrm{~min}$ to complete and the vertical-slice scans about $30 \mathrm{~s}$ or less, depending on the resolution desired and thus the scanning speed selected. An example of vertical-slice scan data from the Lamar project is shown in Fig. 3. In general, the data exhibited a LLJ maximum (e.g., in Fig. 3, it is at $\sim 350 \mathrm{~m}$ ) and the layering was horizontal. However, as pointed out in Newsom and Banta (2003), scan data were sometimes tilted as a result of topographic slope effects, and sometimes the Lamar data indicated dips or humps in the jet maximum across a scan, which were probably also related to local topography.

Analysis of the elevation-scan sequences consisted of assigning measurement data to vertically stacked bins at a constant height interval $\Delta z$, then averaging over all data in each of the horizontally oriented bins (as on Fig. 3). For profiles of the mean wind, bins of $\Delta z=5$ or 10 $\mathrm{m}$ have provided estimates that agree well with wind speed profiles from towers, radar wind profilers, and 

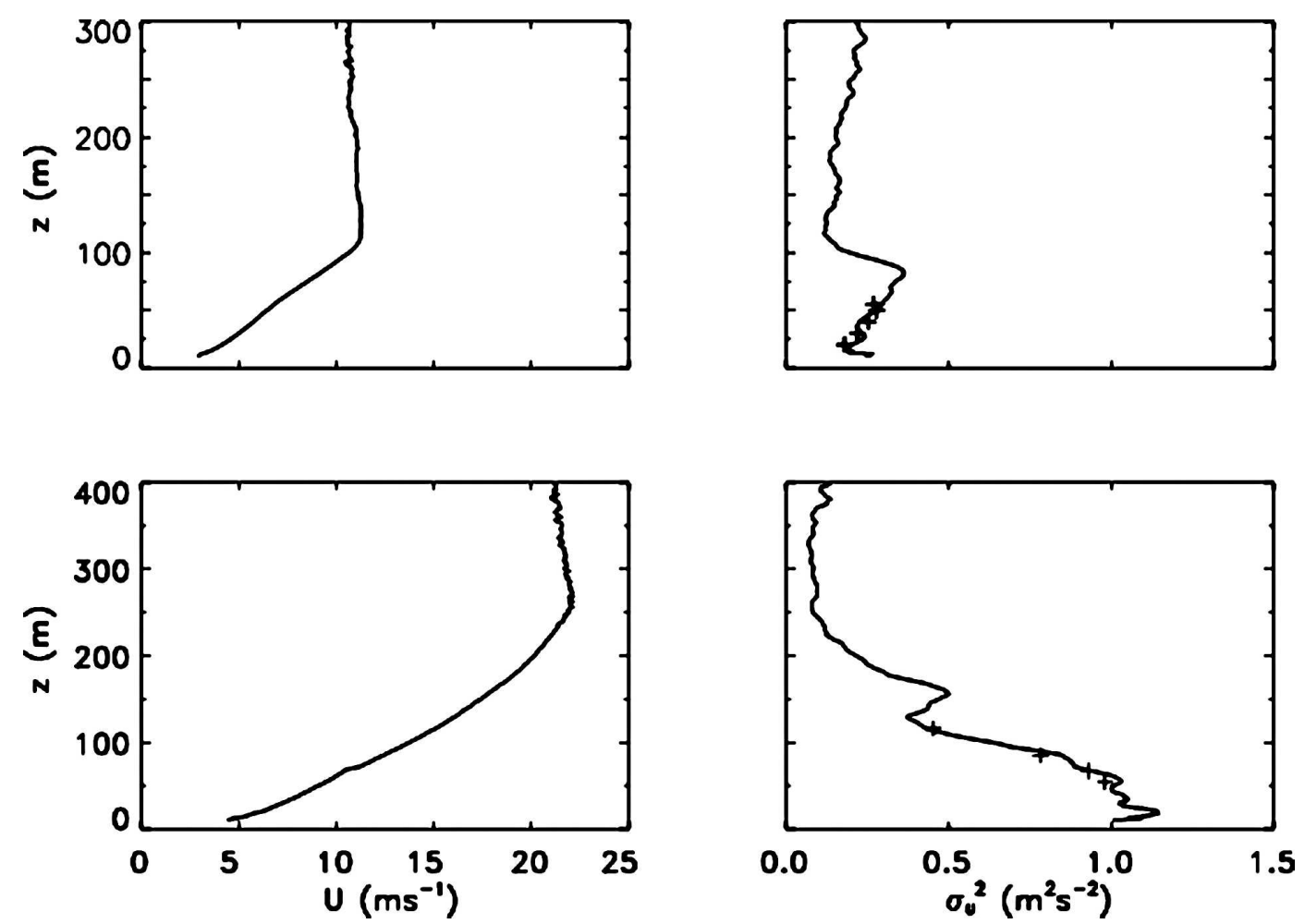

FIG. 4. Ten-minute-averaged vertical profiles of (left) mean wind speed $U(z)\left(\mathrm{m} \mathrm{s}^{-1}\right)$ and (right) streamwise variance $\sigma_{u}^{2}\left(\mathrm{~m}^{2} \mathrm{~s}^{-2}\right)$ calculated from several vertical-slice HRDL scans, similar to that shown in Fig. 3, obtained over a 10-min period. Corresponding tower sonic anemometer TKE data for individual tower levels are indicated by + symbols, plotted according to the same scale as the variances. (top) The CASES-99 night beginning at 0230 UTC 25 Oct, and (bottom) the LLLJP-03 night at 0710 UTC 15 Sep 2003.

balloonborne anemometry. This agreement was routinely independent of the temporal averaging employed.

For estimates of streamwise variance $\sigma_{u}^{2}$, we previously found good agreement under near-neutral conditions between lidar variance profiles calculated in this way and the corresponding variance profiles measured on the 60-m CASES-99 tower (as shown in Fig. 13c of Drobinski et al. 2004). In stable, strongly sheared nocturnal conditions, however, we found that lidar variances overestimated tower-measured streamwise variances or TKE by a factor of 2-3. The narrow beam of the lidar and the large number of data points obtained allowed even finer-scale bins, so we then attempted binning at $\Delta z=1 \mathrm{~m}$, and the agreement improved dramatically (e.g., Fig. 4).

The tower-HRDL turbulence intercomparisons were also sensitive to the temporal averaging procedure, in contrast to the mean profiles. Therefore, for the tower data from the CASES and Lamar datasets, TKE was calculated over 1-min intervals, and 10-min means were then calculated by averaging 10 consecutive 1 -min values, consistent with the procedure devised and recom- mended by Vickers and Mahrt (2003). Temporal averaging was also applied to the vertically binned data from HRDL using 5- and 10-min intervals. Representative comparisons between 10-min HRDL $\sigma_{u}^{2}$ profiles and tower-measured TKE profiles are shown in Fig. 4. Regression analysis of the 5-min data (not shown) yielded correlation coefficients $r^{2}$ of better than 0.75 for the entire dataset (including the profiles not used in this study) and exceeding 0.8 for several individual nights of the study. This agreement was not as good for the 10min averaged data, but the composited profile results and conclusions presented in this study were essentially the same for both. We have chosen composites based on 10-min averaged profiles for presentation here. A more detailed intercomparison study is in preparation.

Overall these successful intercomparisons show that HRDL-measured streamwise variances are a reasonable surrogate for TKE. This could have been anticipated from measurements taken to support local scaling results (Nieuwstadt 1984), according to which the ratios of the variance components are constant with stability under weakly or moderately stable conditions. For example, Bergström and Smedman (1995) found 
TABLE 1. Local-scaling velocity-variance ratios for stable conditions.

\begin{tabular}{|c|c|c|c|c|c|c|}
\hline & $\sigma_{u}^{2} / u_{*}^{2}$ & $\sigma_{v}^{2} / u_{*}^{2}$ & $\sigma_{v}^{2} / \sigma_{u}^{2}$ & $\sigma_{w}^{2} / u_{*}^{2}$ & $\sigma_{w}^{2} / \sigma_{u}^{2}$ & $\sigma_{u}^{2} / \mathrm{TKE}$ \\
\hline Nieuwstadt (1984)* & 4.2 & 2.9 & 0.69 & 2.0 & 0.48 & 1.08 \\
\hline Lenschow et al. (1988) & 4.5 & 4.5 & 1.0 & 3.1 & 0.69 & 1.34 \\
\hline Smedman (1988) & 5.29 & 2.89 & 0.54 & 1.64 & 0.31 & 0.93 \\
\hline Panofsky and Dutton (1984) & 5.76 & 3.61 & 0.63 & 1.56 & 0.27 & 0.95 \\
\hline Bergström and Smedman (1995) & 5.95 & 3.69 & 0.62 & 1.77 & 0.30 & 0.96 \\
\hline Smedman et al. (1995) & 3.6 & 2.56 & 0.71 & 1.0 & 0.28 & 0.99 \\
\hline Mean & 4.9 & 3.4 & 0.70 & 1.8 & 0.39 & 1.04 \\
\hline
\end{tabular}

* Values of $\sigma_{u}^{2} / u_{*}^{2}$ and $\sigma_{v}^{2} / u_{*}^{2}$ obtained from Lenschow et al. (1988).

$\sigma_{u} / u_{*} \sim 2.44, \sigma_{v} / u_{*} \sim 1.92$, and $\sigma_{w} / u_{*} \sim 1.33$ using tower time series data, in approximate agreement with previous work. This would imply $\sigma_{v} / \sigma_{u} \sim 0.79$ and $\sigma_{w} / \sigma_{u} \sim 0.54$, or

$$
\begin{aligned}
\mathrm{TKE} & =0.5\left(\sigma_{u}^{2}+\sigma_{v}^{2}+\sigma_{w}^{2}\right) \\
& =0.5\left(\sigma_{u}^{2}+0.79^{2} \sigma_{u}^{2}+0.54^{2} \sigma_{u}^{2}\right)=0.96 \sigma_{u}^{2} .
\end{aligned}
$$

In other words, for stable conditions as considered in this study, the streamwise variance is proportional to TKE, and the proportionality constant should be close to 1 . The constant derived from data from other studies in stable conditions is also $\sim 1$, as listed in Table 1 . The agreement is because of the factor $1 / 2$ in the TKE definition and the fact that the streamwise variance in stable conditions tends to be larger than the other two components. This result should be independent of selfcorrelation effects (e.g., Mahrt 1999; Klipp and Mahrt 2004) because $u_{*}$ cancels out of the variance ratio calculation.

Advantages of this dataset are that Doppler lidar scan data are available at $\sim 30 \mathrm{~s}$ intervals. The individual 10-min profiles are averages over data from many scans obtained during the interval and they therefore represent more than 30-s "snapshot" profiles from individual scans. Having such averaged profiles available for entire nights provides the ability to observe the evolution of the LLJ structure and SBL turbulence, which is the subject of further studies in progress, as well as to obtain robust statistics.

\section{Results}

\section{a. Individual profiles}

Figure 5 shows individual, 10-min-averaged Doppler lidar profiles of the LLJ wind speed paired with profiles of $\sigma_{u}^{2}$, calculated as described in section 2. In the following discussion, notation for the variables $U, \sigma_{u}^{2}$, and $\sigma_{u}$ will be used interchangeably with their functional form $U(z), \sigma_{u}^{2}(z)$, and $\sigma_{u}(z)$. Individual 10-min mean profiles of $\sigma_{u}^{2}$ through the LLJ exhibit a great many shapes. In the middle of the night, after $\sim 0200-0300$ UTC when LLJ height and speed have become established and the turbulence has become "adjusted" to this height and shear structure, the variance profiles were often characterized by a single peak value below the LLJ maximum. The peak sometimes occurred at the surface and sometimes at a level above the surface.

But the ABL was stable because of interaction with the cold surface, and one of the properties of the SBL is layering of quantities. Some of the profiles, therefore, exhibited layering of the turbulence and sometimes even of the shear magnitude itself with height (Figs. 5e, 6b). Transitions, including the evening transition or the formation of a new LLJ at a new height while the older one waned, could also produce transient layering of the turbulence structure (Fig. 6). Thus, as is the case for the SBL in general, profiles in the layer between the LLJ maximum and the surface are often complicated and show considerable fine structure and temporal variability. A great majority of $\sigma_{u}^{2}$ profiles, however, exhibited a variance maximum in the shear layer below the LLJ nose. Some also had a maximum in a shear layer above the jet nose, as will be described later.

\section{b. Composite adjusted profiles}

Profiles of the mean wind $U(z)$ and the streamwise variance $\sigma_{u}^{2}(z)$ or standard deviation $\sigma_{u}(z)$, composited for all six nights of this study, are shown in Fig. 7. Excluded from the sample were individual 10-min profiles if the profile was not deep enough to accurately determine $Z_{X}$, if the $U(z)$ or $\sigma_{u}^{2}$ profile appeared too noisy, or if the profile was transient, nonadjusted, layered, or other one-of-a kind profiles, such as the layered profiles in Figs. 5e and 6b. Height in all profiles has been nondimensionalized by the height of the lowest LLJ wind maximum $Z_{X}$, which represents the top of the surface-based shear layer or the "momentum BL" as defined by Mahrt et al. (1979). Wind speeds and variances have been nondimensionalized by the speed of the LLJ $U_{X}$, except for the top panels, which retain the dimensions. 
(a) $09 / 05 / 0340$

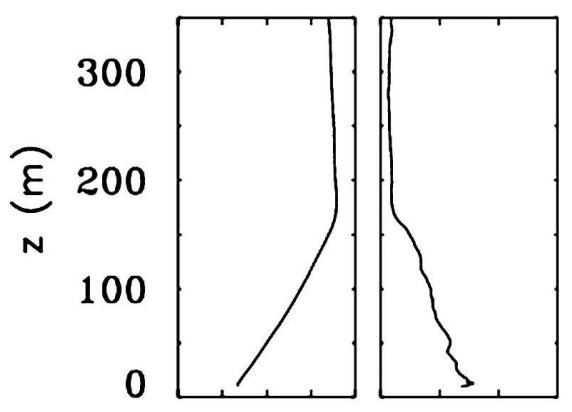

(d) $09 / 15 / 0300$

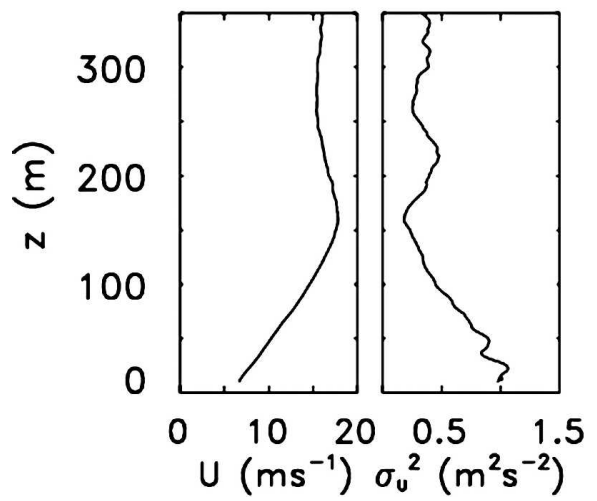

(b) $09 / 15 / 0510$

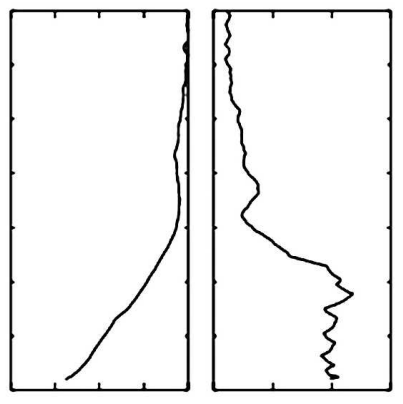

(e) $09 / 05 / 0650$

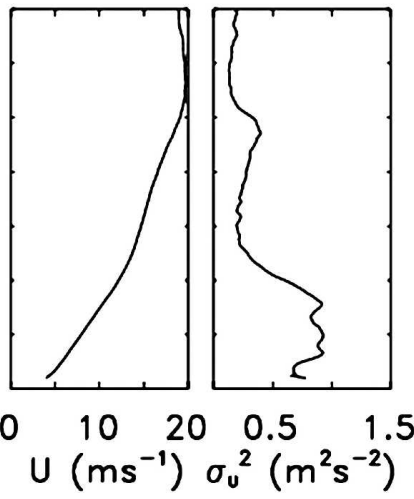

(c) $10 / 25 / 0940$

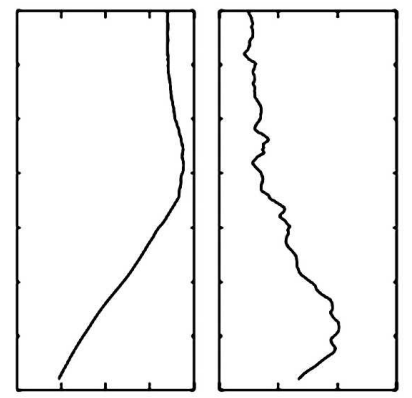

(f) $09 / 06 / 1040$

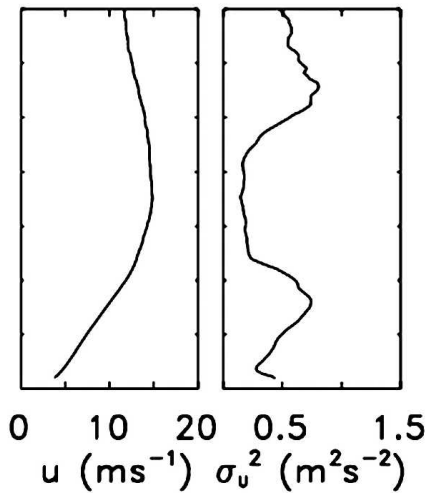

FIG. 5. (left) Lidar-measured, 10-min averaged profiles of mean wind speed and (right) streamwise-velocity variance, for times starting at (a) 0340 UTC 5 Sep, (b) 0510 UTC 15 Sep 2003, (c) 0940 UTC 25 Oct 1999, (d) 0300 UTC 15 Sep, (e) 0650 UTC 5 Sep, and (f) 1040 UTC 6 Sep 2003. October 1999 profile was from CASES-99, and September 2003 profiles were from the Lamar project.

Below the jet the composite normalized $U(z) / U_{X}$ (Fig. 7c) describes the mean-wind profiles with relatively small scatter. The mean $U(z) / U_{X}$ profile in the subjet layer has a slight convex curvature, and the $\left(U / U_{X}\right)^{2}$ profile (Fig. 7e) has a linear to slightly concave curvature. Profiles from subsets of the sample (such as those presented later in the paper) exhibit the same behavior. Thus, if the velocity profile is represented by $U(z) \sim z^{b}$, then $b$ would be between 1 and $1 / 2$. We note that either a linear or a $1 / 2$ power profile is within the scatter of the data. Since by definition $U\left(z_{0}\right)=0$ (where $z_{0}$ is the roughness height for momentum), considerable shear (nearly $35 \%$ ) was concentrated in the lowest $10 \%$ of the subjet layer.

The raw, unnormalized variances $\sigma_{u}^{2}$ are largest near the surface (Fig. 7b). The $\sigma_{u}^{2}$ and $\sigma_{u}$ profiles exhibit a minimum at the LLJ height, where $z / Z_{X}=1$. This relationship is shown clearly in the scatter diagram of the height of the $\sigma_{u}$ minimum $z\left(\sigma_{\min }\right)$ versus the jet height $Z_{X}$ (Fig. 8a). The histogram in Fig. 8b shows that the normalized height of the minimum $z\left(\sigma_{\min }\right) / Z_{X}$ tends to be at the LLJ height, but it can be somewhat above or below. For this reason, the composited minima would have been subjected to some smoothing in height during the averaging process, and the value of the composited minima would not necessarily be as small or distinct as on individual profiles. Figure $8 \mathrm{c}$ seems to indicate that this was not much of a factor, though, as the normalized minima from individual profiles had a median value of $\sim 0.24$, only a little less than the composite minimum from Fig. $7 \mathrm{~d}$.

The appropriate velocity scale for turbulence variables in the moderately or weakly stable boundary layer has traditionally been the surface layer $u_{*}$. To see the effects of nondimensionalizing quantities by $U_{X}$ instead of $u_{*}$ using the same dataset ( $u_{*}$ was not measured in the surface layer during the Lamar project), we used composite profiles from CASES-99 where both quantities were available (Fig. 9). Composite wind and standard deviation profiles normalized by $u_{*}$ and $U_{X}$ are shown in Fig. 9. The fit of the $U_{X}$-scaled, mean-wind profile $U(z) / U_{X}$ (Fig. 9c) is a dramatic improvement over the $u_{*}$-scaled profile (Fig. 9a), as indicated by smaller error bars, and this significant improvement ex- 
a) 0610 UTC
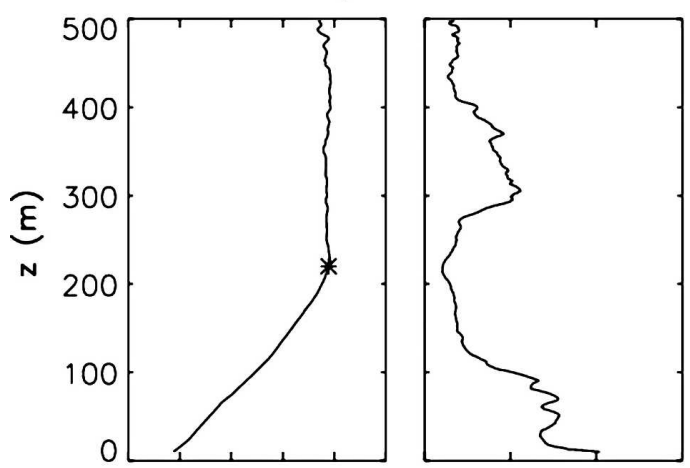

c) 0710 UTC
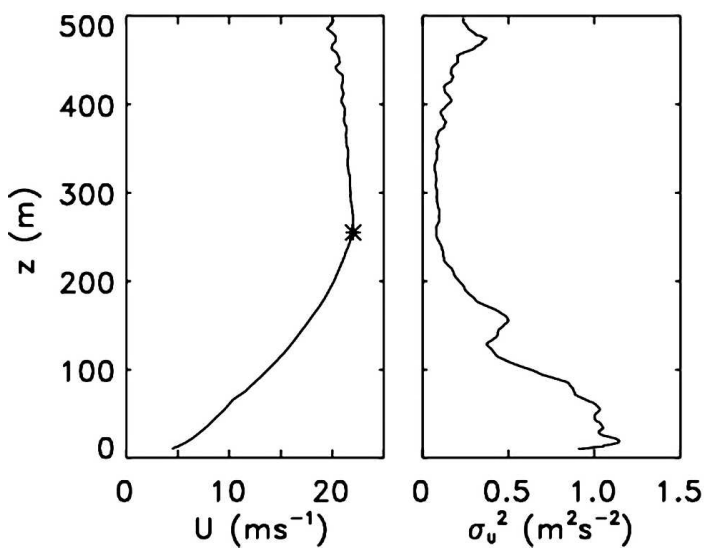

b) 0640 UTC

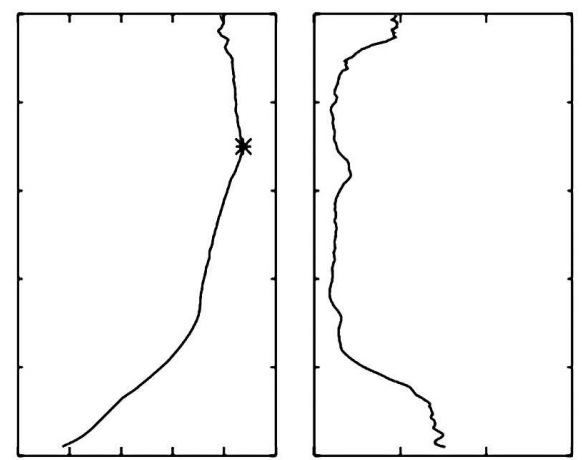

d) 0720 UTC

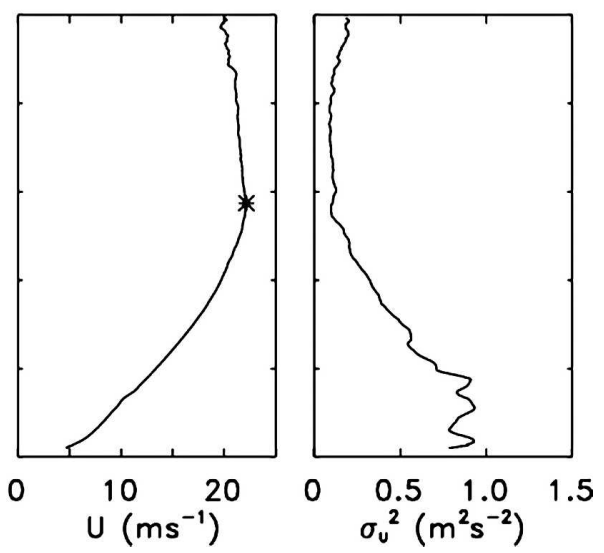

FIG. 6. Sequence of four profiles from 15 September 2003 (Lamar) showing adjustment from a jet height of 220 $\mathrm{m}$ to a height of $290 \mathrm{~m}$ over a period of $70 \mathrm{~min}$. Profiles are shown for (a) 0610, (b) 0640, (c) 0710, and (d) 0720 UTC.

tends down to the lowest level even though $U_{X}$ is measured aloft and $u_{*}$ is a surface layer variable. The fit of the variance profile shows improvement for $\sigma_{u}(z) / U_{X}$ (Fig. 9d) compared with $\sigma_{u}(z) / u_{*}$ (Fig. 9b) near the jet height $z / Z_{X}=1$. Significantly, scaling $\sigma_{u}(z)$ by $U_{X}$ is much better than scaling by $u_{*}$ near the surface, even though $u_{*}$ represents surface layer kinematics. The large variability in the middle of the subjet layer near $z / Z_{X}=0.5-0.7$ is due largely to the many different profile shapes of $\sigma_{u}(z)$ composing the composite. Profiles presented later, based on composites of profiles of similar shape, will show a better fit. Thus, these results indicate that $U_{X}$ as a velocity scale produced an improved fit over $u_{*}$ for kinematic turbulence quantities and a vast improvement for the mean velocity profile, even near the surface.

The range of $u_{*}$ and $U_{X}$ during the strong LLJ nights of CASES-99 is shown in Figs. 10a,b. Here $U_{X}$ was mostly between 12 and $17 \mathrm{~m} \mathrm{~s}^{-1}$, and $u_{*}$ varied mostly from 0.2 to $0.3 \mathrm{~m} \mathrm{~s}^{-1}$. The plot of $u_{*}$ versus $U_{X}$ shows little correlation between the two variables (Fig. 10c). Values of $u_{*}>0.20 \mathrm{~m} \mathrm{~s}^{-1}$ are found to occur over the entire range of $U_{X}$ in the dataset, although values of $U_{X}>16 \mathrm{~m} \mathrm{~s}^{-1}$ tended to be associated with the higher values of $u_{*}$. Since $U_{X}$ tends to vary smoothly in time (Banta et al. 2002), this implies that $u^{*}$ is the more variable quantity. This conclusion is consistent with anecdotal observations of L. Mahrt, based on analyses of tower data from several SBL projects, that near-surface turbulent quantities in the stable surface layer exhibit more erratic temporal and spatial behavior than the same quantities measured at $20-30 \mathrm{~m}$ above ground. This erratic behavior is attributed to the nonequilibrium state of the stable surface layer-the fact that $u_{*}$ and other surface-layer variables "are constantly perturbed by surface heterogeneity, and the near-surface flow has difficulty adjusting to even small changes in surface conditions" (L. Mahrt 2006, personal communication). Thus, an important factor in the poorer performance of $u_{*}$ is likely the erratic behavior of tur- 

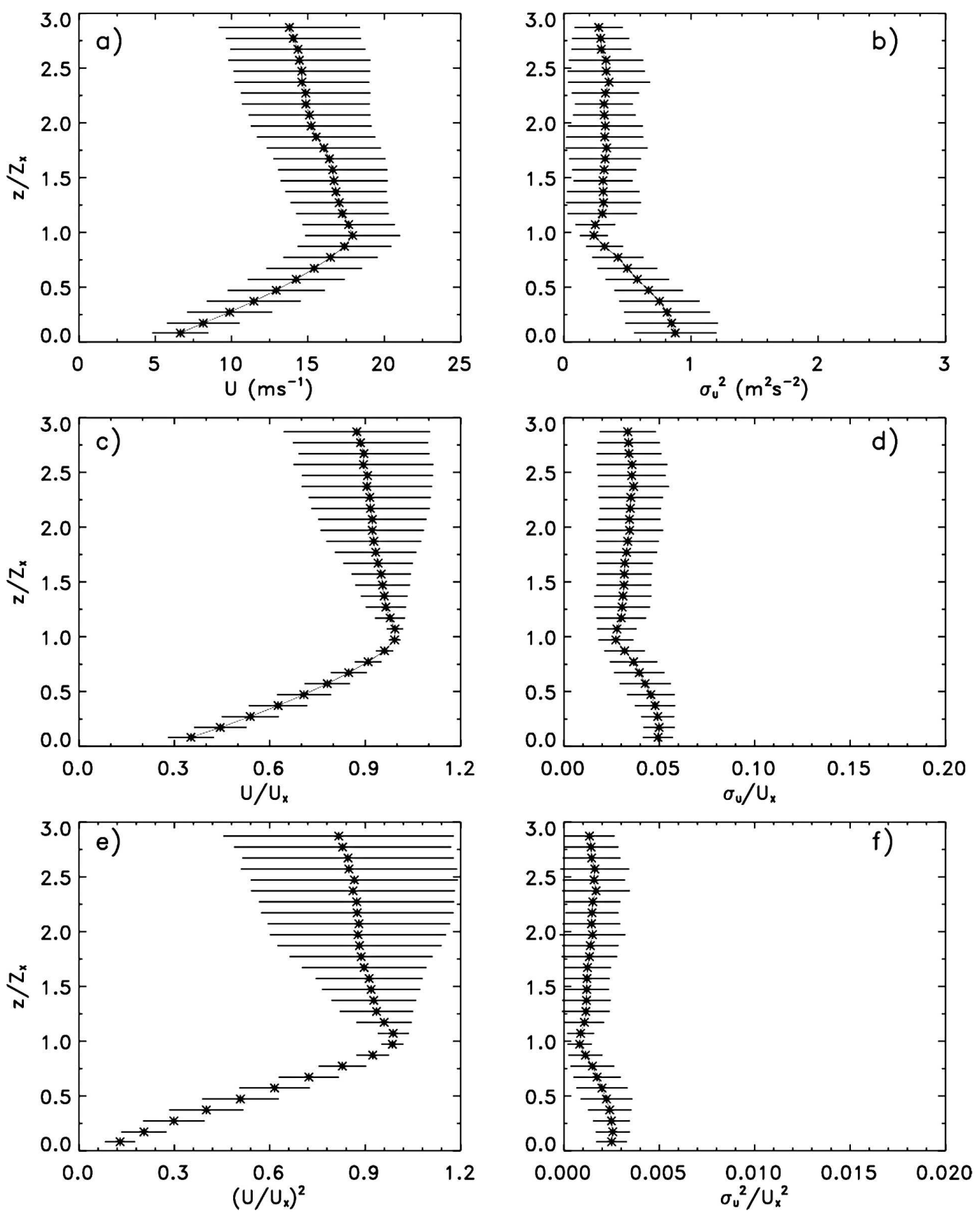

FIG. 7. Composite profiles for all study days (CASES-99 and Lamar), showing (a) wind speed $U\left(\mathrm{~m} \mathrm{~s}^{-1}\right)$, (b) streamwise variance $\sigma_{u}^{2}\left(\mathrm{~m}^{2} \mathrm{~s}^{-2}\right)$, (c) wind speed scaled by LLJ speed $U_{X}$, (d) streamwise standard deviation scaled by $U_{X}$, (e) square of wind speed scaled by $U_{X}^{2}$, and (f) streamwise variance scaled by $U_{X}^{2}$. All heights are normalized by $Z_{X}$, the height of the LLJ. Mean value for each vertical level (for vertical intervals of $0.1 Z_{X}$ ) is indicated by * and horizontal error bar indicates \pm 1 standard deviation for the 10 -min vertical profiles comprising the dataset.

bulence variables, including $u_{*}$, in the stable surface layer.

The fit of the $\sigma_{u}(z) / U_{X}$ profile is especially good near the surface, despite $U_{X}$ being measured well above the surface and despite the fact that the variance itself shows the greatest uncertainty near the surface (Fig. $7 \mathrm{~b})$. The composite maximum value of $\sigma_{u} / U_{X}$ near the ground was 0.05 (Fig. 7d). This value was also found for the composites of the CASES-99 subset (Fig. 9d) and for those of each individual night studied (Fig. 11). For 

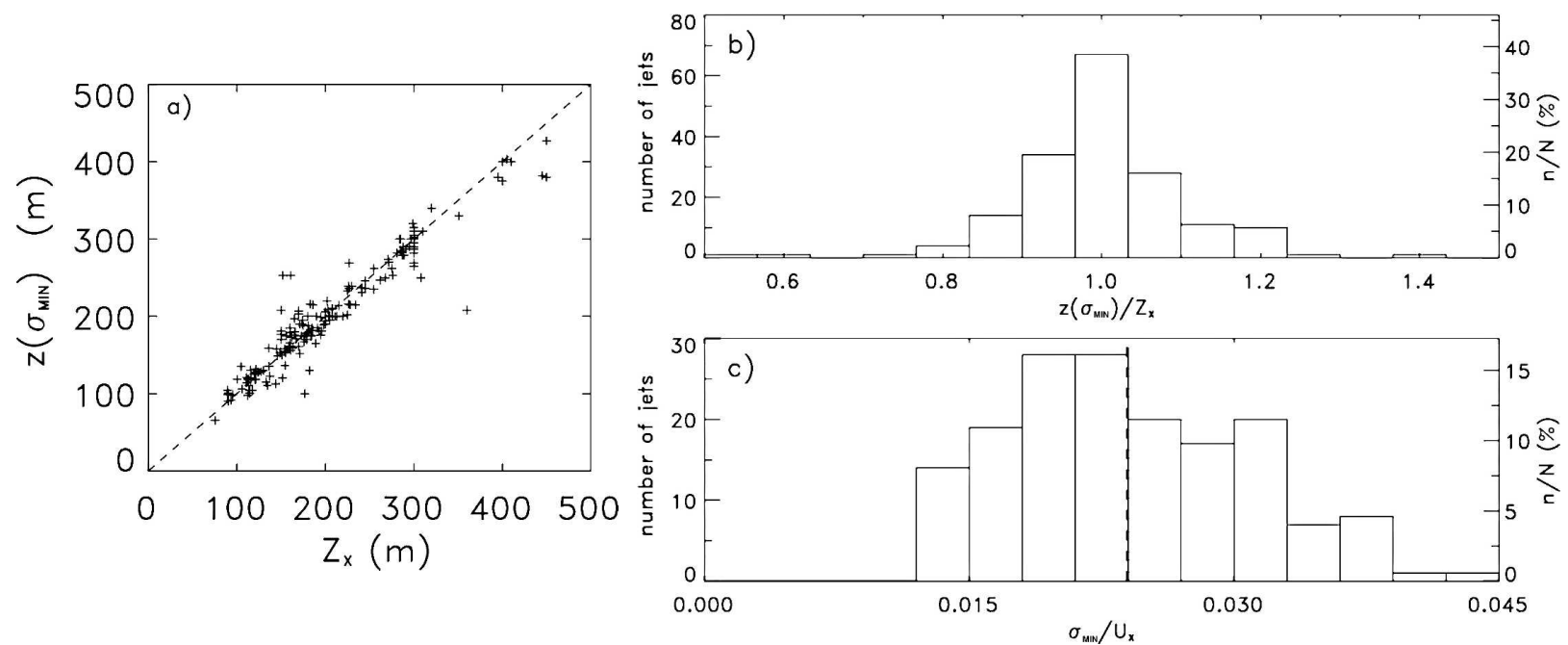

FIG. 8. (a) Scatter diagram of height $z\left(\sigma_{\min }\right)$ of the minimum of $\sigma_{u}(z)$ profile vs height of LLJ maximum $Z_{X}$; (b) Histogram of normalized height of $\sigma_{u}(z)$ profile $z\left(\sigma_{\min }\right) / Z_{X}$; and (c) histogram of $\sigma_{\min } / U_{X}$. The vertical dashed line indicates the median value of the sample of 0.024 .
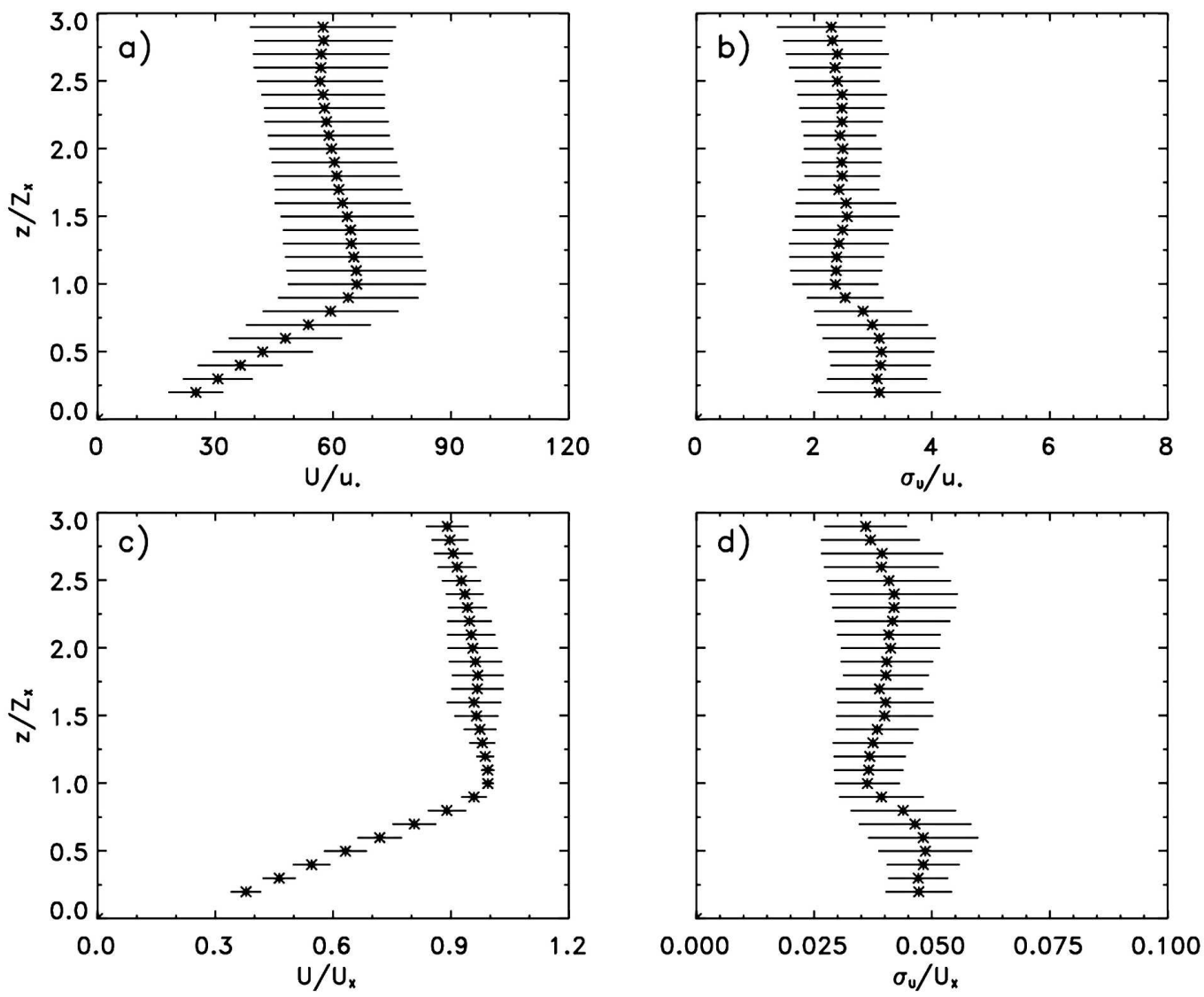

FIG. 9. Composite profiles based only on CASES-99 data for 25 and 27 October. (a) Wind speed $U(z)$ and (b) streamwise standard deviation $\sigma_{u}(z)$ profiles normalized by surface-layer $u_{*} ;(\mathrm{c}) U(z)$ and (d) $\sigma_{u}(z)$ normalized by LLJ speed $U_{X}$. 

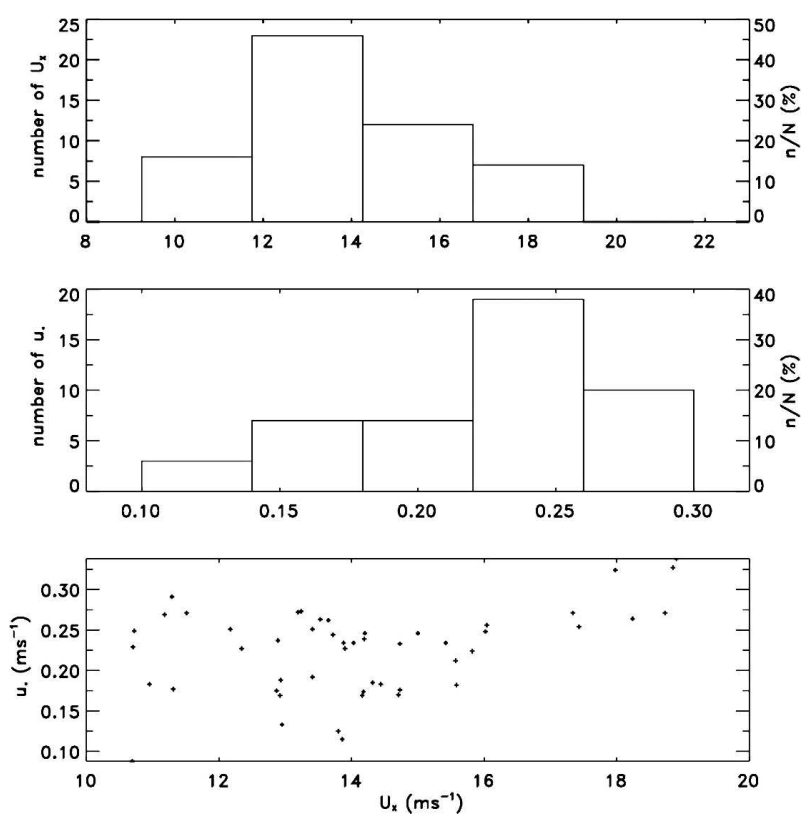

FIG. 10. Histogram of (top) $U_{X}$ and (middle) $u_{*}$ from the two nights of the CASES-99 dataset used in this study. (bottom) A scatter diagram $u_{*}$ vs $U_{X}$ using the same data.

reference, we note that the quantity turbulence intensity, often defined as the standard deviation of the wind speed divided by the speed itself, with both measured at the same level, is generally about 0.1 or a little greater near the earth's surface under near-neutral conditions, so the quantity $\sigma_{u} / U_{X}$ was about half that.

\section{c. Shapes of LLJ wind speed profiles}

LLJ speed profiles assumed a variety of shapes (cf. Figs. 5, 6 of this paper and Fig. 1 of Banta et al. 2002). Most familiar was the nose or single-maximum struc-

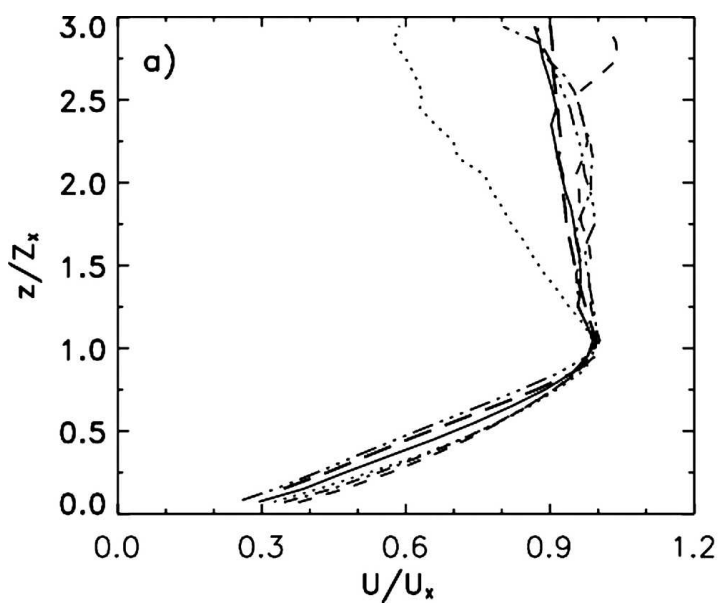

ture as shown in Fig. 12a. On many nights, however, the well-mixed flow in the late-afternoon mixed layer accelerated uniformly with height after sunset to produce a nearly uniform profile of speed with height above $Z_{X}$ in the layer corresponding to the prior mixed layer (Fig. 12c). This uniform acceleration was probably the result of invariant geostrophic winds and ageostrophic forcing with height. In the first case, significant shear is evident above the height of the nose $\left(Z_{X}\right)$, whereas in the second case the shear above $Z_{X}$ was negligible. Intermediate cases, where some shear existed above $Z_{X}$, can also be identified. In this section we form composites of each of these types of profile to illustrate the differences in the shape of the variance profiles.

The composite of the first, single-peak speed profile type is shown in Fig. 12a. The shear zone above $Z_{X}$ produced a strong secondary elevated peak in turbulence variance having about the same magnitude as the primary subjet variance peak (Fig. 12b). This peak in turbulence above the LLJ nose had previously been inferred from Ri profiles by Mahrt et al. (1979), and noted in turbulence measurements by Smedman et al. (1993). Thus, at heights above the LLJ maximum, the shear could produce strong active waves or turbulence and mixing. For example, an incidence of ducted gravity wave activity in the shear layer above the jet was documented during CASES-99 (Fritts et al. 2003).

The composite of the second type, which has little shear above $Z_{X}$, is shown in Fig. 12c. Normalization of the data by $Z_{X}$ and $U_{X}$ produced an especially good fit, as indicated by small error bars for both $U(z)$ and $\sigma_{u}(z)$. The secondary peak in turbulence above $Z_{X}$ is absent (Fig. 12d). Turbulent $\sigma$ values reached a minimum at $Z_{X}$ as seen in the overall composite (Fig. 7), but remained small at heights above $Z_{X}$. Turbulent mixing

FIG. 11. Composite profiles of (a) $U(z) / U_{X}$ and (b) $\sigma_{u}(z) / U_{X}$ for each of the six individual study nights from CASES-99 and Lamar. 

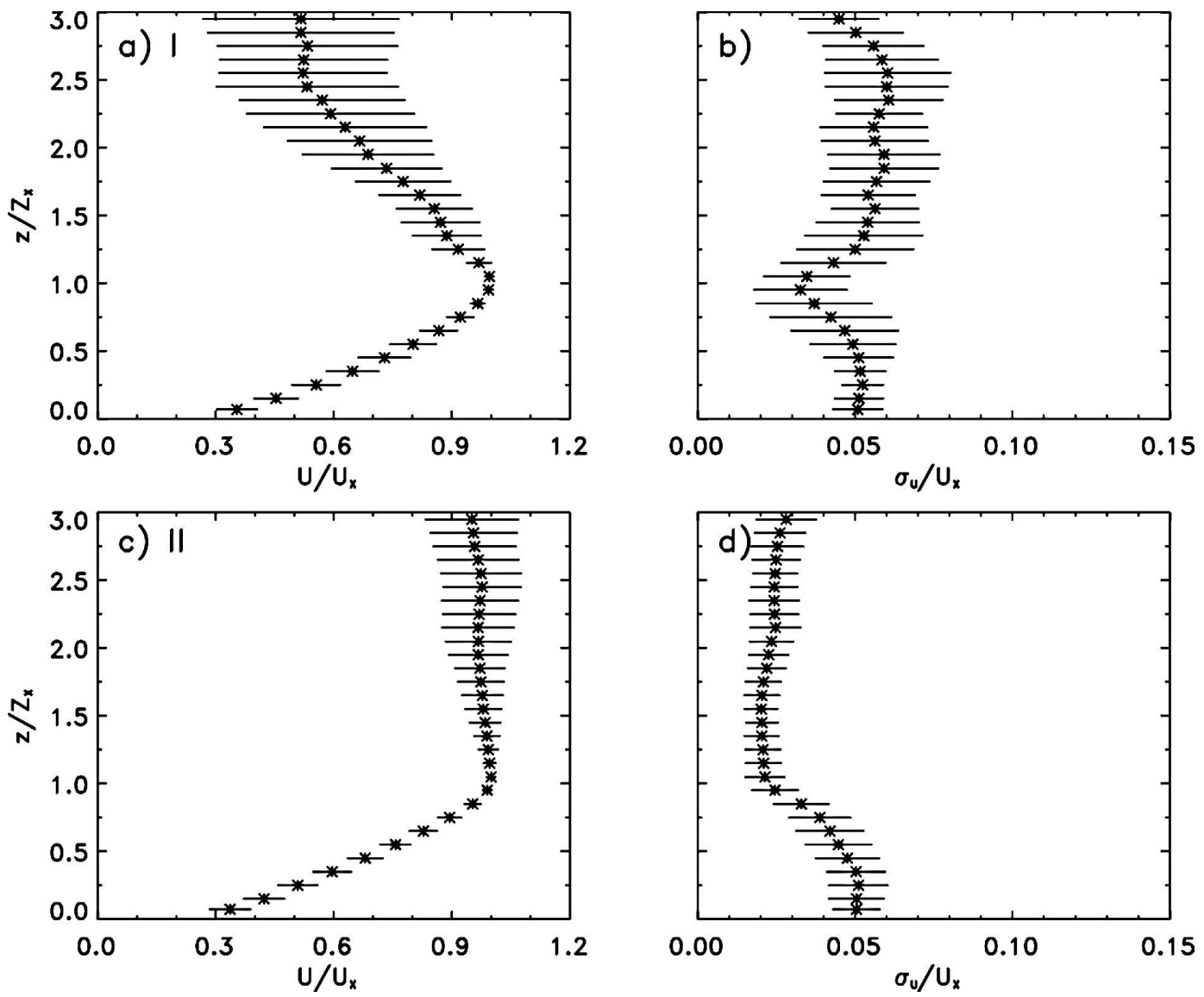

FIG. 12. Composite profiles of mean wind speed and streamwise standard deviation for the two types of wind speed profiles. (a) Mean wind speed $U(z) / U_{X}$ and (b) $\sigma_{u}(z) / U_{X}$ for the first type of profile, with distinct jet nose, representing $12 \%$ of all profiles, and (c) mean wind speed $U(z) / U_{X}$ and (d) $\sigma_{u}(z) / U_{X}$ for the second type of profile, with constant wind speed above $z / Z_{X}=1$, representing $35 \%$ of profiles.

would be small in this layer, but variables could appear well mixed because of the late-afternoon initial profiles. In the intermediate cases (not shown) the nonzero shear above $Z_{X}$ did produce a secondary maximum of $\sigma_{u}(z)$ above the jet nose, but it was weaker than the first case. Thus, unsurprisingly, the magnitude of turbulence in the layer above the LLJ nose was a direct reflection of the magnitude of the shear through that layer.

\section{d. Shapes of variance profiles}

As with the profiles of the mean wind, the sample of $\sigma_{u}$ profiles used in Fig. 7 consisted of many different profile shapes (cf. Figs. 5, 6). Three shapes that were observed more than any others included those with the maximum of $\sigma_{u}$ at the surface decreasing monotonically to a minimum at $Z_{X}$ (e.g., Fig. 5a), profiles with a maximum aloft in the subjet layer (between minima near the surface and at $Z_{X}$; e.g., Figs. 5c,f), and profiles where $\sigma_{u}$ was constant through a portion of the subjet layer (e.g., Figs. $5 b, \mathrm{e})$.

\section{1) Surface maximum (SX)}

Many $\sigma_{u}^{2}$ and $\sigma_{u}$ profiles exhibited traditional boundary layer structure, with the maximum at the surface. These profiles, designated SX, are composited in Fig. 13a,b, where scaling by $U_{X}$ and $Z_{X}$ again produced a very good fit. The value of $\sigma_{u} / U_{X}$ at the surface for this subset was 0.05 , and the value of the minimum $\sigma_{\min } / U_{X}$ averaged 0.02 , so an appropriate linear equation for the variance profile between $z=0$ and $Z_{X}$ is

$$
\sigma_{u}(z) / U_{X}=-0.03 z / Z_{X}+0.05, z / Z_{X} \in[0,1] .
$$

Although the profile appears very close to linear, the data do not rule out profile exponents of 3/4 (Nieuwstadt 1984; Sorbjan 1988) or 7/8 (Lenschow et al. 1988).

\section{2) MaXimum aloft (AX)}

A second subset of profiles had a peak in $\sigma_{u}(z)$ in the subjet layer above the surface (Figs. 13c,d). In these 

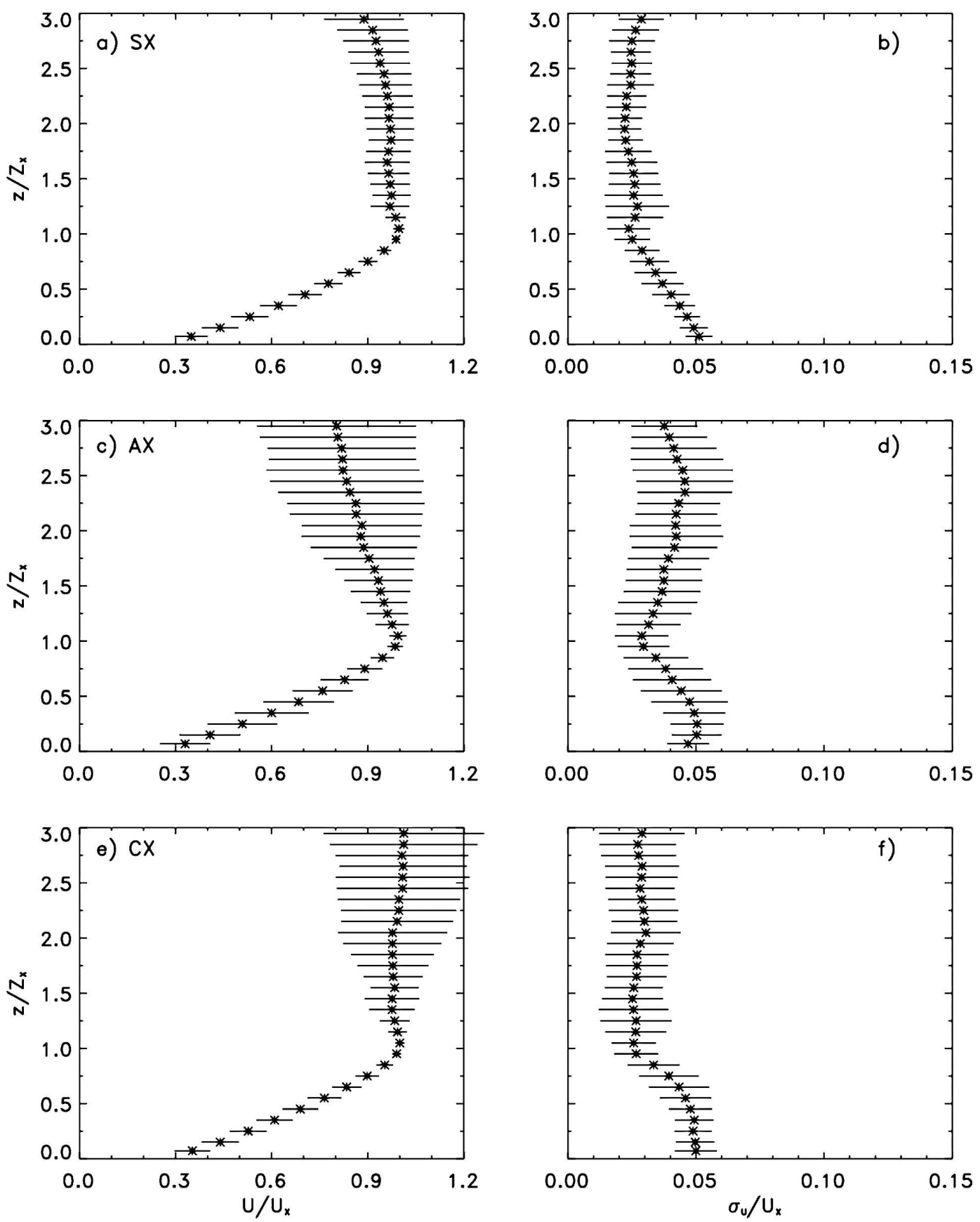

FIG. 13. Composite profiles of (left) normalized wind speed $U(z) / U_{X}$ and (right) normalized streamwise standard deviation $\sigma_{u}(z) / U_{X}$ for (a), (b) profiles where the maximum $\sigma_{u}$ was at the surface (SX, representing $25 \%$ of all profiles), (c), (d) profiles where the maximum $\sigma_{u}$ was above the surface (AX, $49 \%$ of profiles), and (e), (f) profiles where the maximum $\sigma_{u}$ was constant for some depth in the subjet layer (CX, 26\% of profiles).

profiles the values of the $\sigma_{u}$ maxima aloft averaged 0.05 . Since $\sigma_{u}^{2}$ (and therefore TKE) both increase with $z$ below this peak, the AX profiles are the ones associated with upside-down behavior (Mahrt 1999; Mahrt and Vickers 2002). The scatterplot and histogram (Figs. 14a,b) of the height of the variance maxi- mum $z\left(\sigma_{\max }\right)$ show that this peak occurred mostly at 40-80 m regardless of the height of the jet. As a result the normalized $z\left(\sigma_{\max }\right) / Z_{X}$ appears about evenly distributed between 0.1 and 0.7 (Fig. 14c). Most of the uncertainty (error bar) in the composite $\sigma_{u}$ profiles below the jet (Figs. 7d and 9b,d) comes from this subset 

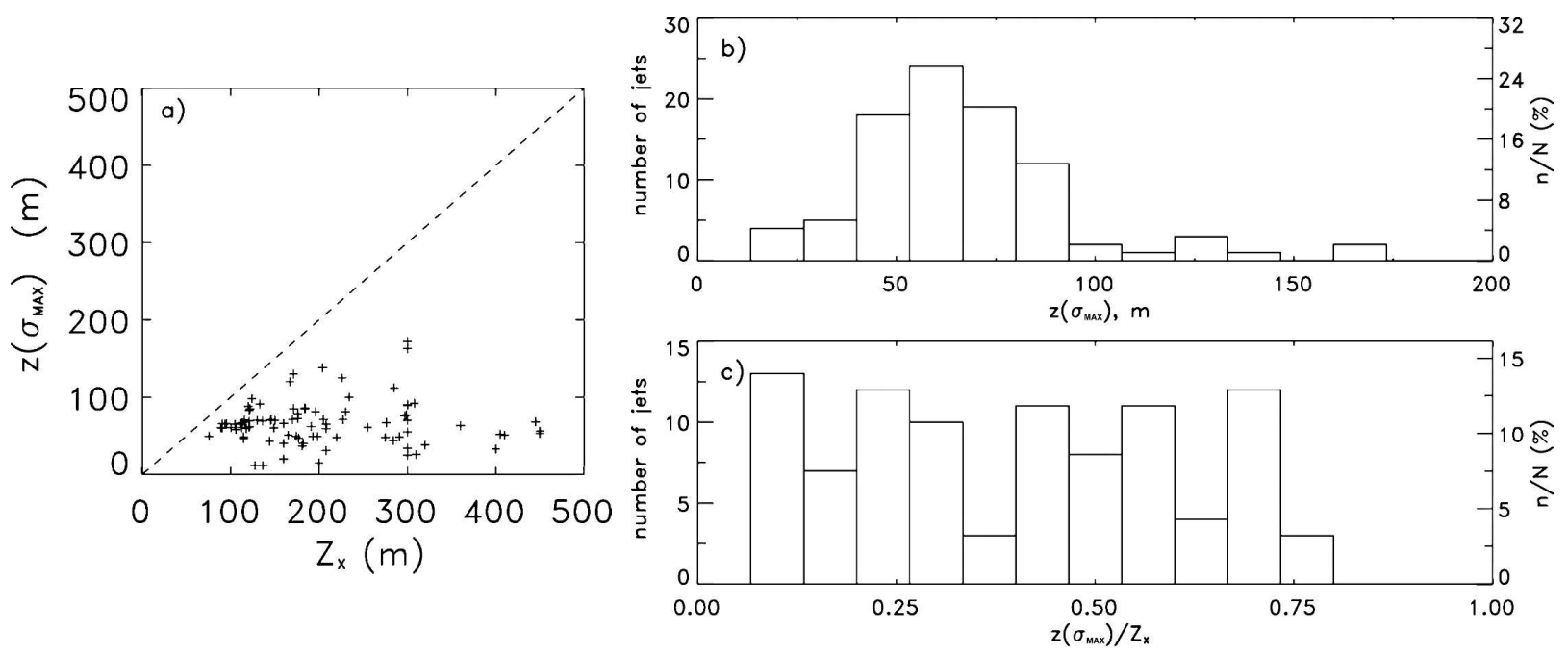

FIG. 14. Statistics related to the height, $z\left(\sigma_{\max }\right)$, of peak value of the streamwise standard deviation in the $\sigma_{u}(z)$ profile for the AX subset only. (a) Scatter diagram of the height of the variance maximum $z\left(\sigma_{\max }\right)$ vs $Z_{X}$; (b) histogram of $z\left(\sigma_{\max }\right)$ and (c) histogram of the normalized height $z\left(\sigma_{\max }\right) / Z_{X}$.

because of the variability of the height of the maximum in $z / Z_{X}$ space.

\section{3) Constant maximum $(\mathrm{CX})$}

A third subset of profiles exhibited a layer of some depth in which the peak $\sigma_{u} /(z) / U_{X}$ values were approximately constant (Figs. 13e,f). Again the maximum has a value of 0.05 . The constant $\sigma_{u}$ layer seen in the individual profiles varied in height and depth, so the composite shows a gently curving profile of $\sigma_{u}$.

Histograms of $\mathrm{Ri}$ measured across the towers for each of the profile shape categories are shown in Fig. 15. The mean Ri for the SX sample was 0.15 for the profiles that exhibited traditional structure. The upsidedown AX category, which had the maximum in variance above the surface, tended to occur under more stable conditions with mean $\mathrm{Ri}=0.19$. The profiles with a constant peak (CX) had stabilities between the other two, averaging 0.17 . Tests of statistical significance were run, showing that, at the $95 \%$ confidence levels, the AX and SX means-the highest and lowest values-were from different populations, that is, the difference was significant. The AX and CX differences were also significant, but the SX and CX differences were not significant.

The differences in profile shape thus appear to be related to differences in stability. The most unstable regime produced vigorous mixing and traditional boundary layer structure, generating a maximum in TKE at the surface. Increased stability would mean that the highest values of TKE, which were produced aloft in the LLJ shear, either did not fully penetrate down to the surface, or that increased stratification at lower levels suppressed turbulence activity there.

\section{Discussion}

A significant finding of this study is that the peak $\sigma_{u}$, or alternatively $\sigma=\mathrm{TKE}^{1 / 2}$, can be expressed as a frac-
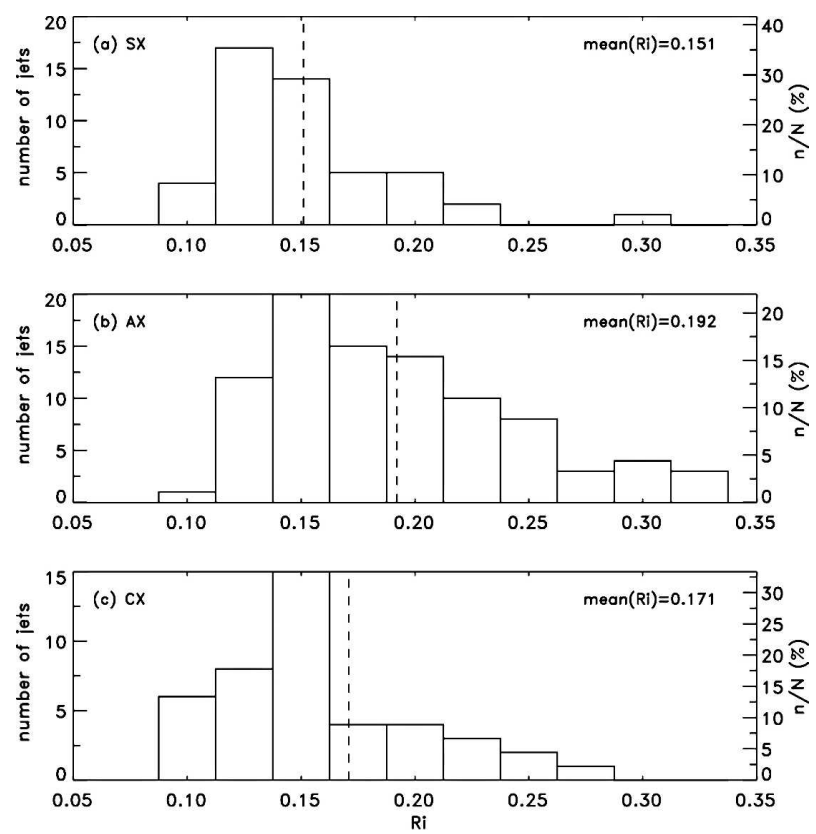

FIG. 15. Histograms of bulk Ri values for (a) SX subset, with maximum $\sigma_{u}$ at the surface, (b) AX subset, with maximum $\sigma_{u}$ aloft, and (c) CX subset, with constant maximum of $\sigma_{u}$. The vertical line in each panel represents the mean value of $\mathrm{Ri}$ for each sample. 
TABLE 2. Measured ratios of variance to LLJ speed.

\begin{tabular}{lcccc}
\hline \hline & $U_{X}\left(\mathrm{~m} \mathrm{~s}^{-1}\right)$ & TKE $\left(\mathrm{m}^{2} \mathrm{~s}^{-2}\right)$ & $\sigma\left(\mathrm{m} \mathrm{s}^{-1}\right)$ & $\sigma / U_{X}$ \\
\hline Mahrt et al. (1979) & 8 & 0.075 & 0.27 & 0.034 \\
Lenschow et al. (1979) & 12 & 0.2 & 0.45 & 0.037 \\
& 22 & $0.4,0.9$ & $0.63,0.95$ & $0.029,0.043$ \\
& 28 & $0.5,1.1$ & $0.71,1.05$ & $0.025,0.038$ \\
Tjernström and Smedman (1993) & 12.1 & $0.22^{*}$ & 0.47 & 0.039 \\
& 4.8 & $0.1^{*}$ & 0.31 & 0.064 \\
Smedman et al. (1995)** & 10.1 & $0.27^{*}$ & 0.52 & 0.051 \\
& 15.4 & 0.50 & 0.71 & 0.046 \\
Ohya et al. (1997) & 5.0 & 0.10 & 0.47 & 0.064 \\
Mean & 18.4 & & 0.025 \\
\end{tabular}

$*$ Value is of streamwise variance $\sigma_{u}^{2}$.

** First profile omitted.

tion of the speed of the first LLJ maximum above the surface (corresponding to the top of the shear layer or momentum BL). That fraction equaled about $5 \%$ (or $\left.U_{X} / 20\right)$. This result is consistent with laboratory data (e.g., Ohya et al. 1997) if $U_{X}$ is equated with the freestreamflow speed $U_{\infty}$. But an important question is how general is this finding; that is, is there any support for it in other atmospheric measurements? Simultaneous measurements of $U_{X}$ and $\sigma$ are available from a few studies. Most of the estimates were from aircraft slantpath profiles, which Smedman et al. (1993) characterized as a snapshot of the atmosphere. This sampling technique clearly is a valid representation of the vertical structure only to the extent that the atmosphere is both stationary and horizontally homogeneous during the periods of ascent or descent, which was generally on the order of $10 \mathrm{~min}$ over distances on the order of 10 $\mathrm{km}$. Advantages and limitations of this technique are discussed by Mahrt (1985) and Tjernström and Smedman (1993). Often TKE data were not available down to near the surface, so these profiles may underestimate the maximum $\sigma$ values.

Estimates of $U_{X}$ and $\sigma$ from several studies are shown in Table 2. Ratios of $\sigma / U_{X}$ from individual profiles range from 0.025 to 0.064 , and the average for all profiles is $\sim 0.04$. Considering the differences in locations and sampling techniques, this appears to be impressive agreement with the results of our study.

Another finding of this study was that the $\sigma_{u}$ profile for the least stable cases tended to have traditional boundary layer structure with a maximum at the surface but, as stability increased slightly, the $\sigma_{u}$ peak became elevated. The same tendency is evident in the wind tunnel profiles of Ohya et al. (1997) and Ohya (2001). Another unresolved issue in the atmosphere, which was addressed in the laboratory studies, is the role of surface roughness. In the first study (Ohya et al. 1997) the wind-tunnel lower boundary surface was smooth, whereas in the second (Ohya 2001), the surface was considerably roughened. In the first study peak values of $u^{\prime} / U_{\infty}$, which is the same as $\sigma_{u} / U_{X}$ in our study, range from 0.05 to $\sim 0.07$, whereas in the second all but one of the moderately to weakly stable runs have peak values of $\sigma / U_{\infty}$ from 0.06 to 0.08 (the least stable nonneutral run had a peak ratio of between 0.09 and 0.10 ). Thus, if these results are transferable to the atmosphere, we should expect only incremental increases in the $\sigma / U_{X}$ ratio as a result of even significant roughness increases.

The minimum in TKE (and $\sigma_{u}^{2}$ ) at the LLJ nose results from $\partial U(z) / \partial z$ becoming 0 at this level and from the consequent peak in $\mathrm{Ri}$, as noted by Mahrt et al. (1979). Shear production of TKE must vanish at $Z_{X}$, but it is not necessarily true that TKE also vanishes there, or that no vertical mixing occurs through this level. Data in the present study indicate that $\sigma_{u}^{2}$ became small but remained nonzero at $Z_{X}$, but this conclusion is not resolved in the literature. Profiles shown by Nieuwstadt (1984), Lenschow et al. (1988), and Sorbjan (1988) show near-zero values of turbulence at the top of the SBL, whereas profiles presented by Smedman et al. (1993) and in the wind tunnel (Ohya et al. 1997; Ohya 2001) show diminished but distinctly nonzero values of turbulence at the SBL top. Nonzero turbulence at $Z_{X}$ (or $h$ ) would imply some vertical transport through this level, and this transport could be further augmented by nonstationarity in the speed of the LLJ as shown by Banta et al. (2002, cf. their Fig. 15). Such nonstationary pulsations could produce alternating divergenceconvergence, which could pump SBL air vertically through the $Z_{X}$ level. These vertical transport mechanisms may provide a partial explanation for the growth 
of the top of the temperature inversion $Z_{I}$ above $Z_{X}$, which Mahrt et al. (1979) also attribute to effects of the vertical moisture distribution on the radiative cooling profile.

\section{Conclusions}

The results of this study indicate that it would be better to view the turbulent SBL as a downward extension of LLJ-generated shear effects, rather than an upward extension of surface layer turbulence for nights of the CASES-99 and Lamar field projects when the jet speed was $>15 \mathrm{~m} \mathrm{~s}^{-1}$. In particular, the streamwise variance $\sigma_{u}^{2}$ and by inference TKE scaled better with the LLJ speed $U_{X}$ than with the surface layer $u_{*}$. What was impressive about this scaling was that the fit for $U_{X}$ scaling was better near the surface even though $U_{X}$ was measured aloft and $u_{*}$ was measured near the surface. The appropriate SBL scaling height was $Z_{X}$.

Although individual mean $\sigma_{u}^{2}$ profiles showed considerable variability in shape, we identified three shapes that occurred more often than others: traditional boundary layer structure with maximum turbulence at the surface, profiles with constant $\sigma_{u}^{2}$ through a significant depth of the subjet layer; and profiles exhibiting the maximum $\sigma_{u}^{2}$ aloft. A significant result of this study was that the magnitude of the composited peak of the ratio $\sigma_{u} / U_{X}$ was 0.05 for each subset and for each individual night, as well as for the composite of all profiles from all nights. Results from previous field studies, where both turbulence profiles and LLJ wind profiles were available, were consistent with this finding. The profiles thus exhibited similarity not only in profile shape, but also in the magnitude of the turbulence.

The profile shapes showed a dependence on stability (bulk $\mathrm{Ri}$ ) with the more stable profiles having a peak aloft and the least stable having the peak at the surface. This dependence suggests a worthwhile series of numerical [large-eddy simulation (LES) or direct numerical simulation (DNS)] sensitivity experiments in which the surface cooling (stability) is altered to see if the model can reproduce CX or AX structure. Such models seem to be able to reproduce traditional boundary layer structure (SX), but it would be illuminating to determine what conditions of stability or other factors were necessary to reproduce upside-down or constantvariance turbulence profiles.

These results demonstrate how critical it is to measure up through heights above $Z_{X}$ in field studies of the weakly-to-moderately stable BL. Implications for modeling depend on the scale of the model. For LES or DNS studies of the SBL, these findings show the importance of properly representing the LLJ and its prop- erties and that the depth of the simulation must extend to heights above $Z_{X}$. For meso- and larger-scale numerical weather prediction models, it follows from this study that the key to accurate representation of turbulence intensity in the weakly stable boundary layer is an accurate prediction of the strength of the LLJ. The encouraging aspect of this result is that, after the evening decoupling process is completed, the mixing intensity is more dependent on larger-scale controls than on details of near-surface turbulence parameterizations. On the larger-scale, accurate prediction of LLJ speed requires proper representation of the ageostrophic wind profile at sunset and proper representation of the stabilization process, including the decoupling of the flow from surface friction during the early evening transition. Accurate turbulence magnitudes require a subresolutionscale flux scheme that faithfully describes the relationship between the turbulence quantities and the shear plus other gradients. From the roughly linear profiles of $U$ and $\theta$ through most of the subjet layer, it appears that the gradients are also controlled by large-scale processes; for example, the shear was shown to be reasonably well estimated as $U_{X} / Z_{X}$.

A final important question is to what extent is the development of the nocturnal jet affected by smallscale variability in topography or surface properties, and horizontal inhomogeneities in surface cooling or friction? Evidence from CASES-99 (Banta et al. 2002) and more recent studies suggests that these influences may not be very important. The jet speed is often relatively constant or slowly varying in time on most nights after the evening transition. Also, after the transition, the height of the jet was shown to tend to be geopotentially level over a region of at least many tens of kilometers, where the topography was dominated by gently rolling hills with gullies. This implies that areawide stabilization by areawide surface cooling is what is required for the frictional decoupling process, and localized cold, warm, or rough spots are largely immaterial to this process. Once again, these results suggest that a mesoscale or somewhat larger-scale NWP model should be able to represent the turbulence structure of the strong-LLJ SBL, if the late-afternoon ageostrophic wind and the decoupling processes are properly represented.

Acknowledgments. Support for the analysis in this study, which has taken place over several years' time, came from a number of sources, including the U.S. Army Research Office (ARO, Dr. Walter Bach) of the Army Research Laboratory under Proposal 43711-EV, and the National Renewable Energy Research Laboratory (NREL, Dr. Neil D. Kelley) of the U.S. Depart- 
ment of Energy (DOE) under Interagency Agreement DOE-AI36-03GO13094. Further analysis and manuscript preparation were supported by the Office of Science (BER), U.S. Department of Energy, under Interagency Agreement DE-AI02-04ER63860 (VTMX), and the NOAA Health of the Atmosphere program. Field data acquisition for the Lamar project was funded by DOE/NREL. Field data acquisition for the CASES99 project was supported by ARO under Proposal 40065-EV, the Cooperative Institute for Research in the Atmosphere (Center for Geosciences/Atmospheric Research), and the National Science Foundation under Grant ATM-9908453. We are indebted to our colleagues from the NOAA/ESRL lidar group for contributions to HRDL preparation and setup and data acquisition during CASES and Lamar, including Alan Brewer, Volker Wulfmeyer, Scott Sandberg, Janet Machol, Brandi McCarty, Joanne George, Raul Alvarez, Andreas Muschinski, Jennifer Keane, Ann Weickmann, Ron Richter, R. M. Hardesty, J. Otten, W. Eberhard, and M. Pichugin; and Lisa Darby. We also thank Ms. Darby for a very helpful manuscript review, and Jielun Sun, Sean Burns, Steve Oncley, and Ned Chamberlain of NCAR for tower and sounding data. The following individuals from NREL ensured the success of the Lamar project: Neil D. Kelley, Mari Shirazi, Dave Jager, S. Wilde, and J. Adams.

\section{REFERENCES}

Andreas, E. L, K. J. Claffey, and A. P. Markshtas, 2000: Low-level atmospheric jets and inversions over the western Weddell Sea. Bound.-Layer Meteor., 97, 459-486.

Balsley, B. B., R. G. Frehlich, M. L. Jensen, and Y. Meillier, 2006: High-resolution in situ profiling through the stable boundary layer: Examination of the SBL top in terms of minimum shear, maximum stratification, and turbulence decrease. $J$. Atmos. Sci., 63, 1291-1307.

Banta, R. M., and Coauthors, 1998: Daytime buildup and nighttime transport of urban ozone in the boundary layer during a stagnation episode. J. Geophys. Res., 103, 22 519-22 544.

— , R. K. Newsom, J. K. Lundquist, Y. L. Pichugina, R. L. Coulter, and L. Mahrt, 2002: Nocturnal low-level jet characteristics over Kansas during CASES-99. Bound.-Layer Meteor., 105, 221-252.

— , Y. L. Pichugina, and R. K. Newsom, 2003: Relationship between low-level jet properties and turbulence kinetic energy in the nocturnal stable boundary layer. J. Atmos. Sci., 60, 2549-2555.

— N. N. D. Kelley, and Y. L. Pichugina, 2004: Low-level jet properties and turbulence below the jet during the Lamar LowLevel-Jet Project. Preprints, 16th Symp. on Boundary Layers and Turbulence, Portland, ME, Amer. Meteor. Soc., CDROM, 4.10.

— Meteor. Soc., 86, 657-669.

Bergström, H., and A.-S. Smedman, 1995: Stably stratified flow in a marine atmospheric surface layer. Bound.-Layer Meteor., 72, 239-265.

Beyrich, F., 1994: Sodar observations of the stable boundary layer height in relation to the nocturnal low-level jet. Meteor. Z., 3, 29-34.

Blackadar, A. K., 1957: Boundary layer wind maxima and their significance for the growth of nocturnal inversions. Bull. Amer. Meteor. Soc., 38, 283-290.

Blumen, W., R. M. Banta, S. P. Burns, D. C. Fritts, R. Newsom, G. S. Poulos, and J. Sun, 2001: Turbulence statistics of a Kelvin-Helmholtz billow event observed in the nighttime boundary layer during the CASES-99 field program. Dyn. Atmos. Oceans, 34, 189-204.

Browning, K. A., and R. Wexler, 1968: The determination of kinematic properties of a wind field using Doppler radar. $J$. Appl. Meteor., 7, 105-113.

Caughey, S. J., J. C. Wyngaard, and J. C. Kaimal, 1979: Turbulence in the evolving stable boundary layer. J. Atmos. Sci., 36, 1041-1052.

Drobinski, P., P. Carlotti, R. K. Newsom, R. M. Banta, R. C. Foster, and J.-L. Redelsperger, 2004: The structure of the nearneutral atmospheric surface layer. J. Atmos. Sci., 61, 699-714.

Fritts, D. C., C. Nappo, C. M. Riggin, B. B. Balsley, W. E. Eichingre, and R. K. Newsom, 2003: Analysis of ducted motions in the stable nocturnal boundary layer during CASES-99. $J$. Atmos. Sci., 60, 2450-2472.

Grachev, A., C. W. Fairall, P. O. G. Persson, E. L Andreas, and P. S. Guest, 2005: Stable boundary-layer scaling regimes: The SHEBA data. Bound.-Layer Meteor., 116, 201-235.

Grund, C. J., R. M. Banta, J. L. George, J. N. Howell, M. J. Post, R. A. Richter, and A. M. Weickmann, 2001: High-resolution Doppler lidar for boundary layer and cloud research. $J$. Atmos. Oceanic Technol., 18, 376-393.

Högström, U., and A.-S. Smedman, 1984: The wind regime in coastal areas with special reference to results from the Swedish wind energy program. Bound.-Layer Meteor., 30, 351-373.

Holtslag, A. A. M., and F. T. M. Nieuwstadt, 1986: Scaling the atmospheric boundary layer. Bound.-Layer Meteor., 36, 201209.

Kelley, N. D., M. Shirazi, D. Jager, S. Wilde, J. Adams, M. Buhl, P. Sullivan, and E. Patton, 2004: Lamar low-level jet project interim report. Tech. Rep. NREL/TP-500-34593, National Renewable Energy Laboratory, Golden, CO, $182 \mathrm{pp}$.

Klipp, C. L., and L. J. Mahrt, 2004: Flux-gradient relationships, self-correlation and intermittency in the stable boundary layer. Quart. J. Roy. Meteor. Soc., 130, 2087-2104.

Kosović, B., and J. Curry, 2000: A large eddy simulation study of a quasi-steady, stably stratified atmospheric boundary layer. J. Atmos. Sci., 57, 1052-1068.

Lenschow, D. H., X. S. Li, C.-J. Zhu, and B. B. Stankov, 1988: The stably stratified boundary layer over the Great Plains. I. Mean and turbulent structure. Bound.-Layer Meteor., 42, 95121.

Mahrt, L., 1985: Vertical structure and turbulence in the very stable boundary layer. J. Atmos. Sci., 42, 2333-2349.

- 1998: Stratified atmospheric boundary layers and breakdown of models. J. Theor. Comput. Fluid Dyn., 11, 263-280.

_ 1999 : Stratified atmospheric boundary layers. Bound.-Layer Meteor., 90, 375-396.

, and D. Vickers, 2002: Contrasting vertical structures of nocturnal boundary layers. Bound.-Layer Meteor., 105, 351-363.

- , R. C. Heald, D. H. Lenschow, B. B. Stankov, and I. Troen, 
1979: An observational study of the structure of the nocturnal boundary layer. Bound.-Layer Meteor., 17, 247-264.

— - J. Sun, W. Blumen, T. Delaney, and S. Oncley, 1998: Nocturnal boundary layer regimes. Bound.-Layer Meteor., 88, 255-278.

Mason, P. J., and S. H. Derbyshire, 1990: Large-eddy simulation of the stably-stratified atmospheric boundary layer. Bound.Layer Meteor., 53, 117-162.

Newsom, R. K., and R. M. Banta, 2003: Shear-flow instability in the stable nocturnal boundary layer as observed by Doppler lidar during CASES-99. J. Atmos. Sci., 60, 16-33.

_ and _ 2004a: Assimilating coherent Doppler lidar measurements into a model of the atmospheric boundary layer. Part I: Algorithm development and sensitivity to measurement error. J. Atmos. Oceanic Technol., 21, 1328-1345.

$\longrightarrow$, and _ 2004b: Assimilating coherent Doppler lidar measurements into a model of the atmospheric boundary layer. Part II: Sensitivity analyses. J. Atmos. Oceanic Technol., 21, 1809-1824.

Nieuwstadt, F. T. M., 1984: The turbulent structure of the stable, nocturnal boundary layer. J. Atmos. Sci., 41, 2202-2216.

Ohya, Y., 2001: Wind-tunnel study of atmospheric stable boundary layers over a rough surface. Bound.-Layer Meteor., 98, $57-82$.

— D. D. Neff, and R. N. Meroney, 1997: Turbulence structure in a stratified boundary layer under stable conditions. Bound.-Layer Meteor., 83, 139-161.

Panofsky, H. A., and J. A. Dutton, 1984: Atmospheric Turbulence. John Wiley and Sons, 389 pp.

Pichugina, Y. L., R. M. Banta, N. D. Kelley, S. P. Sandberg, J. L. Machol, and W. A. Brewer, 2004: Nocturnal low-level jet characteristics over southeastern Colorado. Preprints, 16th Symp. on Boundary Layers and Turbulence, Portland, ME, Amer. Meteor. Soc., CD-ROM, 4.11.

Poulos, G., and Coauthors, 2002: CASES-99: A comprehensive investigation of the stable nocturnal boundary layer. Bull. Amer. Meteor. Soc., 83, 555-581.

Saiki, E. M., C.-H. Moeng, and P. P. Sullivan, 2000: Large-eddy simulation of the stably stratified planetary boundary layer. Bound.-Layer Meteor., 95, 1-30.
Smedman, A.-S., 1988: Observations of a multi-level turbulence structure in a very stable atmospheric boundary layer. Bound.-Layer Meteor., 44, 231-253.

—, M. Tjernström, and U. Högström, 1993: Analysis of the turbulence structure of a marine low-level jet. Bound.-Layer Meteor., 66, 105-126.

— H. Bergström, and U. Högström, 1995: Spectra, variances and length scales in a marine stable boundary layer dominated by a low-level jet. Bound.-Layer Meteor., 76, 211-232.

- - - and B. Grisogono, 1997: Evolution of stable internal boundary layers over a cold sea. J. Geophys. Res., 102, 10911099.

—, U. Högström, and J. C. R. Hunt, 2004: Effects of shear sheltering in a stable atmospheric boundary layer with strong shear. Quart. J. Roy. Meteor. Soc., 130, 31-50.

Sorbjan, Z., 1988: Structure of the stably-stratified boundary layer during the SESAME-1979 experiment. Bound.-Layer Meteor., 44, 255-266.

Sun, J., and Coauthors, 2002: Intermittent turbulence associated with a density current passage in the stable boundary layer. Bound.-Layer Meteor., 105, 199-219.

- and Coauthors, 2004: Intermittent turbulence in stable boundary layers and the processes that generate it. Bound.Layer Meteor., 110, 255-279.

Tjernström, M., and A.-S. Smedman, 1993: The vertical turbulence structure of the coastal marine atmospheric boundary layer. J. Geophys. Res., 98 (C3), 4809-4826.

Van de Weil, B. J. H., A. Moene, O. Hartogensis, H. A. R. de Bruin, and A. A. M. Holtslag, 2003: Intermittent turbulence in the stable boundary layer over land. Part III: A classification for observations during CASES-99. J. Atmos. Sci., 60, 2509-2522.

Vickers, D., and L. Mahrt, 2003: The cospectral gap and turbulent flux calculations. J. Atmos. Oceanic Technol., 20, 660-672.

—, and - 2006: A solution for flux contamination by mesoscale motions with very weak turbulence. Bound.-Layer Meteor., 118, 431-447.

Wulfmeyer, V. O., M. Randall, W. A. Brewer, and R. M. Hardesty, 2000: $2 \mu \mathrm{m}$ Doppler lidar transmitter with high frequency stability and low chirp. Opt. Lett., 25, 1228-1230. 